
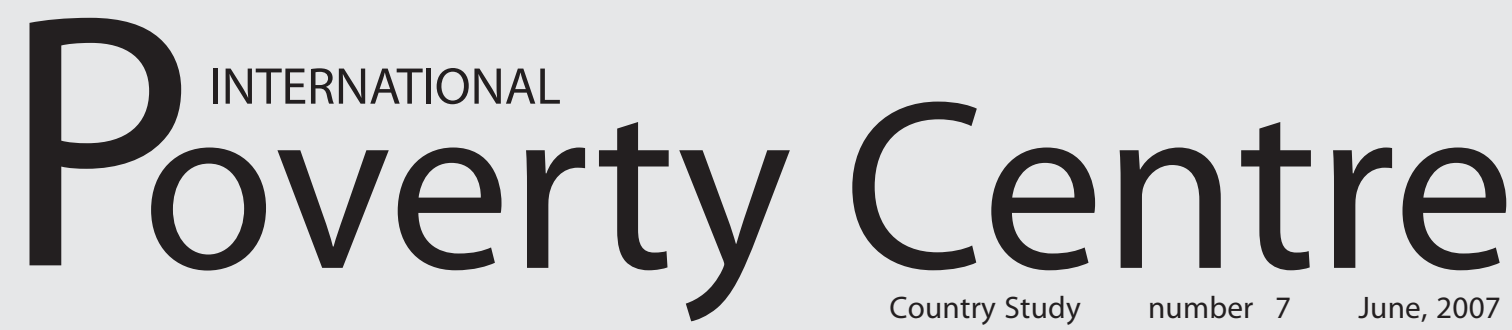

The International Poverty Centre is jointly supported by the Brazilian Institute for Applied Economic Research (IPEA) and the Bureau for Development Policy, United Nations Development Programme, New York.

\title{
THE IMPACT OF GROWTH AND REDISTRIBUTION ON POVERTY AND INEQUALITY IN SOUTH AFRICA
}

\author{
Kalie Pauw and Liberty Mncube \\ Development Policy Research Unit (DPRU), \\ University of Cape Town
}




\title{
Copyright $\odot 2007$
}

\section{International Poverty Centre \\ United Nations Development Programme}

\author{
International Poverty Centre \\ SBS - Ed. BNDES, $10^{\circ}$ andar \\ 70076900 Brasilia DF \\ Brazil \\ povertycentre@undp-povertycentre.org \\ www.undp-povertycentre.org \\ Telephone +55 6121055000 \\ Fax +556121055001
}

\section{Rights and Permissions}

All rights reserved.

The text and data in this publication may be reproduced as long as the source is cited. Reproductions for commercial purposes are forbidden.

The International Poverty Centre disseminates these Country Studies of the Cash Transfer Research Programme to encourage the exchange of ideas about development issues. These studies are signed by the authors and should be cited accordingly. The findings, interpretations, and conclusions that they express are those of the authors. They do not necessarily represent the views of the International Poverty Centre, IPEA or the United Nations Development Programme, its Administrator, Directors, or the countries they represent.

Country Studies of the Cash Transfer Research Programme are available online at http://www.undppovertycentre.org and subscriptions can be requested by email to povertycentre@undp-povertycentre.org 


\title{
THE IMPACT OF GROWTH AND REDISTRIBUTION ON POVERTY AND INEQUALITY IN SOUTH AFRICA
}

\author{
Kalie Pauw and Liberty Mncube*
}

\begin{abstract}
CASH TRANSFER RESEARCH PROGRAMME
This study was generously financed by the UNDP Regional Bureau for Africa. This study is part of a much larger research programme: "Growth, Inequality, Poverty and Cash Transfers: A comparative study of Poverty Impacts and Institutional Aspects in Selected Countries in Africa and Latin America", supported by the Department for International Development of the UK Government (DFID), GTZ and UNDP.
\end{abstract}

\begin{abstract}
This country study evaluates the experience of the South African economy with respect to growth, poverty and inequality trends since the advent of democracy in 1994. The postapartheid government took a definite turn toward greater spending on social security, while job creation and a narrowing of the gap between the so-called first and second economies the latter defined as the informal part of the economy that is also largely removed from formal sector activities - enjoyed priority in its economic strategy. Despite this focus on uplifting the poor, it remains unclear to what extent the government has been successful. Some controversy exists around whether relatively fewer South Africans are poor ten years after the democratic government came into power. There seems to be greater consensus among analysts that inequality has in fact increased. This study attempts to shed some light on these issues, drawing on recent South African literature and data.
\end{abstract}

* The authors are from the Development Policy Research Unit (DPRU) at the University of Cape Town. Comments by Haroon Bhorat (DPRU) and Jean Le Nay (UNDESA) are greatly appreciated. 


\section{INTRODUCTION}

South Africa is officially classified as an upper middle-income country. Certainly, as measured by its per capita income, the average South African citizen appears to be fairly well-off compared to international standards for developing countries. However, the country is also characterised by extreme degrees of inequality in the distribution of income, assets and opportunities. Past discriminatory policies have left a large proportion of the population outside the economic mainstream and relatively poor compared to an elite minority. Since the transition to democracy in 1994, various redistributive policies have been put in place, specially focusing on labour and capital markets, and including affirmative action and broadbased black economic empowerment. However, even with these policies in place, it appears that overall inequality has increased further, albeit not necessarily along racial lines.

Many analysts, however, share the sentiment that this high degree of relative poverty (or inequality) should not overshadow the high incidence of absolute poverty that persists in the country. Depending on how 'absolute poverty' is defined, rates between 45 and 55 per cent of the population are often quoted in the literature (see for example Hoogeveen and Özler, 2004; May, 1998; Taylor, 2002; Woolard and Leibbrandt, 2001). While most policymakers agree that the underlying structural causes of poverty are best addressed by long-term strategies designed to give people access to opportunities and income-generating assets, there is also a widespread realisation that certain temporary relief measures are necessary in order to assist the "particularly vulnerable" in society (Taylor, 2002:43). As a result, the last few years have seen a significant rise in expenditure on social security programmes as a direct measure to reduce poverty. However, state resources are limited, and the issue whether social security provisioning can be sustained or expanded further keeps being hotly debated in the policy arena today.

This paper is structured as follows: Section 2 reviews poverty and inequality trends during the last ten years. In section 3, more attention is focused on the nature of the economic growth experienced in South Africa during this period, in an attempt to determine whether such growth was in fact pro-poor or not. Also reviewed in this section is some of the important labour market trends observable in the last decade, and how these have impacted on poverty and inequality. Section 4 explores the role of cash transfers - including pensions, disability grants and various child care grants - in relieving poverty. Some conclusions are then drawn in section $5 .{ }^{1}$

\section{POVERTY AND INEQUALITY IN THE POST-APARTHEID ERA}

\subsection{A PROFILE OF THE SOUTH AFRICAN POPULATION, 1995 - 2000}

When the ANC government came into power in 1994 it inherited a fragmented society and faced daunting socio-economic reforms. Some of the key challenges included regenerating a stagnating economy just emerging from isolation and addressing the socio-economic divide (Van der Berg et al., 2005). The latter challenge involved "breaking down the barriers that exclude people from participating in the economy on the grounds of race, gender or location" (Leibbrandt et al., 2001:21).

Income poverty in its simplest sense is usually defined as the "inability [of an individual or household] to attain a minimal standard of living", with standard of living being measured in terms of consumption or income levels (Woolard and Leibbrandt, 2001:42). A broader 
definition of poverty might consist of a variety of components, including household income/consumption, human capabilities, access to public services, employment and asset ownership. The introduction of non-income measures of poverty provides a more complete assessment of poverty in its different dimensions. Given the focus of this country study, as well as the complexities involved in measuring poverty in a non-monetary framework, the analysis made here considers only income poverty. We also steer clear of the debate on where precisely an appropriate poverty line should be drawn by studying individuals from five different household quintiles. These quintiles are formed around the $20^{\text {th }}, 40^{\text {th }}, 60^{\text {th }}$ and $80^{\text {th }}$ percentiles of household per capita income. Quintile one thus contains the poorest 20 per cent of individuals, quintile two the next poorest 20 per cent, and so forth. For pragmatic reasons, and given the widespread use of the approach, we consider individuals in the bottom two household quintiles to be 'poor', with those in the bottom quintile defined as the 'ultra poor'. Given this approach, the cut-off per capita income level between the second and third quintiles can be regarded as some kind of relative poverty line. ${ }^{2}$

The following sections briefly discuss the social, demographic, geographic and labour market characteristics of the different household quintiles in 1995 and 2000. The Income and Expenditure Survey (IES) of 1995 and 2000, as well as the October Household Survey (OHS) of 1995 and the Labour Force Survey (LFS) of 2000, are used for the analysis. ${ }^{3}$

\subsubsection{Demographics}

Table 1 shows some basic features of the household quintiles in 1995. About 28.7 per cent of the people lived in the poorest 20 per cent of households. Out of the estimated 40.3 million South Africans in 1995, 20.9 million (52 per cent) were relatively poor according to our definition, while the richest 20 per cent of the households (quintile five) contained only 12.7 per cent of the overall population. This reflects the fact that the average size of households in the poorest quintile is much larger than in the others. In fact, in 1995 it was double that of the richest quintile. Also important to note is the much lower average number of workers per household in the lower quintiles. This illustrates the strong linkages between unemployment and poverty that exist in South Africa. The table also illustrates the extreme degree of inequality that exists in the country. The average annual per capita income in the highest quintile was roughly 36 times that of the first quintile.

TABLE 1

Basic Features of Household Per Capita Quintiles in 1995

\begin{tabular}{|c|c|c|c|c|c|c|}
\hline Characteristic & $\begin{array}{c}\text { Quintile } \\
1 \\
\end{array}$ & $\begin{array}{c}\text { Quintile } \\
2\end{array}$ & $\begin{array}{c}\text { Quintile } \\
3\end{array}$ & $\begin{array}{c}\text { Quintile } \\
4\end{array}$ & $\begin{array}{c}\text { Quintile } \\
5\end{array}$ & All \\
\hline Share of households (\%) & 20 & 20 & 20 & 20 & 20 & 100 \\
\hline Share of population (\%) & 28.7 & 23.4 & 19.3 & 15.9 & 12.7 & 100 \\
\hline Household size & 6.4 & 5.2 & 4.3 & 3.5 & 2.8 & 4.4 \\
\hline Number of workers per household & 0.8 & 1.3 & 1.7 & 1.8 & 1.9 & 1.4 \\
\hline Average child/adult ratio & 0.4 & 0.3 & 0.3 & 0.2 & 0.2 & 0.3 \\
\hline Number (000's) & 11561.3 & 9425 & 7789.2 & 6428.8 & 5125.8 & 40330.1 \\
\hline Avg. per capita income (R/annum) & 1223.9 & 2757.3 & 5472.4 & 12402.4 & 44592.8 & 9696.7 \\
\hline \multicolumn{7}{|l|}{ Weighed figures, $n=125,906$} \\
\hline
\end{tabular}

Source: IES/OHS 1995. 
By 2000 , the share of the population in (relatively) ultra-poor households had increased to 32.2 per cent (see Table 2). Out of the estimated 43.3 million South Africans in 2000, 55.6 per cent lived in the bottom two quintiles, compared to 52.1 per cent in 1995. This, of course, is not evidence of an increase in the absolute poverty rate, but merely suggests that a larger share of the population now live in households that are, according to our definition, relatively poor. The average annual per capita income in the highest quintile was roughly 45 times that of the first quintile. This is indicative of a worsening income inequality during the period 1995 to 2000.

TABLE 2

Basic Features of Household Per Capita Quintiles in 2000

\begin{tabular}{|l|r|r|r|r|r|r|}
\hline Characteristic & Quintile 1 & Quintile 2 & Quintile 3 & Quintile 4 & Quintile 5 & All \\
\hline Share of households (\%) & 20 & 20 & 20 & 20 & 20 & 100 \\
Share of population (\%) & 32.2 & 23.5 & 17.1 & 14.4 & 12.9 & 100 \\
Household size & 6.0 & 4.5 & 3.4 & 2.9 & 2.5 & 3.8 \\
Number of workers per household & 0.8 & 1 & 1.1 & 1.3 & 1.4 & 1.1 \\
Average child/adult ratio & 0.4 & 0.3 & 0.3 & 0.2 & 0.1 & 0.3 \\
Number (000's) & 13928.1 & 10168.6 & 7386.6 & 6224.1 & 5594.4 & 43301.7 \\
Avg. per capita income (ZAR/annum) & 1330 & 3236.8 & 6450.1 & 14444.9 & 60781.1 & 12218.1 \\
\hline Weighed figures, $n=104,100$ &
\end{tabular}

Source: IES/LFS 2000.

The issue of household size and poverty deserves closer attention. In absolute terms, households in all quintiles became smaller or more fragmented over time, with the average household size dropping from 4.4 in 1995 to 3.8 in 2000. This result is confirmed by the South African National Censuses conducted in 1996 and 2001, which show a decline in the average household size from 4.1 to 3.8 between these years. Given the apparent correlation between household size and welfare levels, the expectation may thus be that poverty would have declined between 1995 and 2000. However, Bhorat et al. (2004) find no such positive relationship, arguing that complex relationships involving a massive unemployment problem, little social security for those of working age who cannot find jobs and excessive household stress caused by additional factors such as the HIV/AIDS pandemic may all play a role.

Lanjouw and Ravallion (1995) also warn that the relationship between household size and poverty is not clear cut, with empirical results being sensitive to assumptions and value judgments. Clearly this relationship is much more complex, stretching beyond issues of the poor having on average more children (see child to adult ratios in the preceding tables), to include the clustering of extended family networks around limited income resources, and encompassing issues pertaining to economies of scale associated with the consumption of public household goods when a larger number of people live together.

Figure 1 shows the urban-rural composition of households in 1995 and 2000. Just over half of the South African population (51.1 per cent) lived in urban areas. Particularly noteworthy is the relation between income quintiles and location. The ultra poor represented 79.1 per cent of the population who lived in rural areas, in contrast with just 20.9 per cent of ultra poor living in urban areas. Conversely, the richest quintile accounted for just 12.6 per cent of individuals who lived in rural areas, but for as much as 87.4 per cent of individuals in urban areas. 
FIGURE 1

\section{Composition of Household Quintiles by Location in 1995 and 2000}

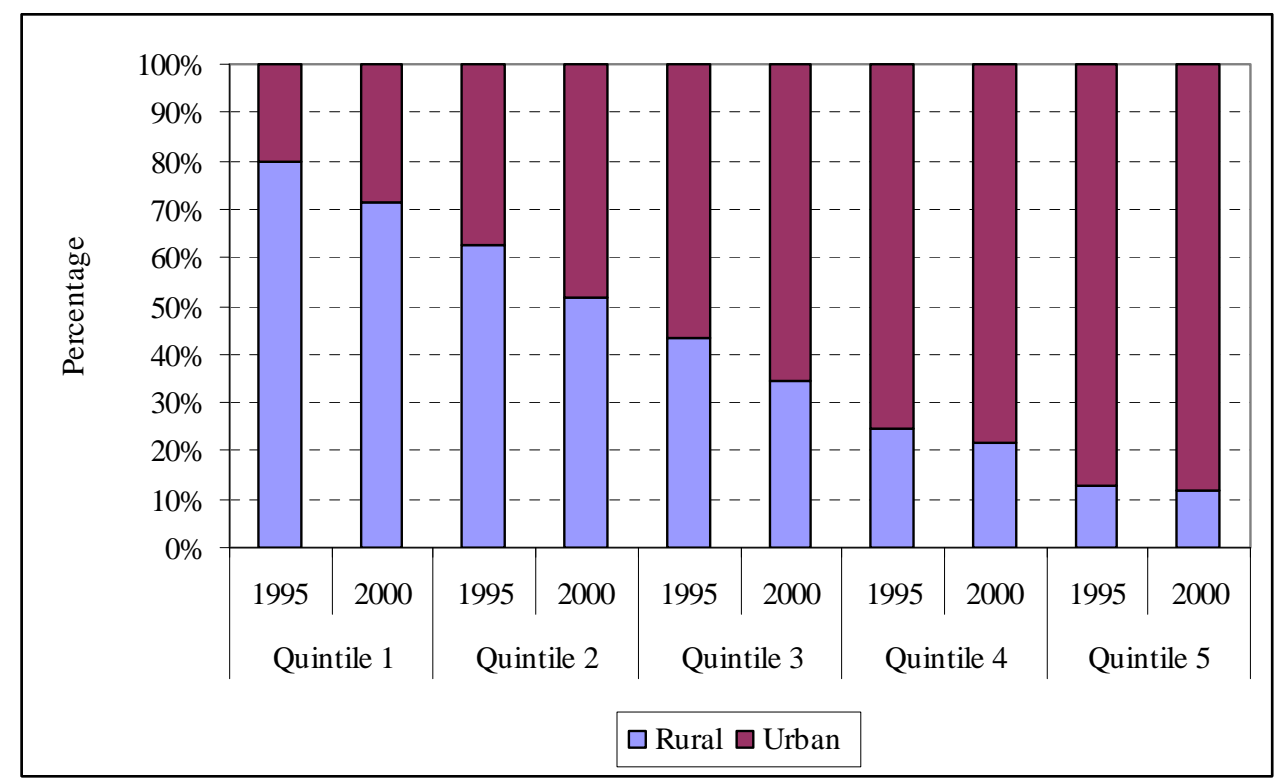

Source: IES/OHS 1995.

The urban-rural ratio has not changed much between 1995 and 2000, although there is some evidence of urbanisation taking place. The share of the population living in urban areas increased slightly from 51.1 per cent in 1995 to 54.5 per cent in 2000. The ultra poor represented 71.3 per cent of the population who lived in rural areas, in contrast with just 28.6 per cent in urban areas.

Poverty was also unevenly distributed among South Africa's provinces between 1995 and 2000. Table 3 (page 6) shows that the Eastern Cape, KwaZulu-Natal and Limpopo had the largest concentration of individuals in quintiles one and two in 1995. The Eastern Cape accounted for 27.5 per cent of the ultra poor, followed by KwaZulu-Natal, with 19.7 per cent. In contrast, 42.0 per cent of the richest quintile lived in Gauteng. This pattern was largely unchanged by 2000, with the Eastern Cape, KwaZulu-Natal and Limpopo still being home to the largest concentration of individuals from the poor quintiles. Large parts of the Eastern Cape and KwaZulu-Natal provinces were formerly part of the so-called Bantustans or homelands, including Transkei, Ciskei and KwaZulu. These areas were formed under the apartheid policy of earmarking areas where Africans were forced to live under a system of selfrule. Clearly, the decades of underfunding, poor management, and economic and geographical isolation of these areas still have an impact on welfare levels of households living there today.

As far as the racial composition of household quintiles are concerned, Figure 2 (page 6) shows that more than 95 per cent of the population in the poor quintiles (one and two) belonged to either the African or Coloured population groups in 1995. These two population groups were clearly overrepresented in the poor quintiles, given that they jointly accounted for 85 per cent of the total population. Conversely, only 28 per cent of the richest quintile was either African or Coloured, in contrast with a disproportional 67 per cent who were Whites. 
TABLE 3

Composition of Household Quintiles by Province in 1995 and 2000

\begin{tabular}{|l|r|r|r|r|r|r|r|r|r|r|r|r|}
\hline & \multicolumn{2}{|c|}{ Quintile 1 } & \multicolumn{2}{c|}{ Quintile 2 } & \multicolumn{2}{c|}{ Quintile 3 } & \multicolumn{2}{c|}{ Quintile 4 } & \multicolumn{2}{c|}{ Quintile 5 } & \multicolumn{2}{c|}{ Total } \\
\hline & $\mathbf{1 9 9 5}$ & $\mathbf{2 0 0 0}$ & $\mathbf{2 0 0 5}$ & $\mathbf{2 0 1 0}$ & $\mathbf{2 0 1 5}$ & $\mathbf{2 0 2 0}$ & $\mathbf{2 0 2 5}$ & $\mathbf{2 0 3 0}$ & $\mathbf{2 0 3 5}$ & $\mathbf{2 0 4 0}$ & $\mathbf{2 0 4 5}$ & $\mathbf{2 0 5 0}$ \\
\hline Western Cape & 2.7 & 2.5 & 8.4 & 7.0 & 13.3 & 11.1 & 13.6 & 12.0 & 14.5 & 15.5 & 9.3 & 9.6 \\
\hline Eastern Cape & 27.5 & 25.0 & 16.7 & 16.1 & 10.7 & 10.3 & 8.9 & 6.9 & 7.4 & 7.2 & 16.2 & 13.1 \\
\hline Northern Cape & 1.7 & 1.3 & 2.3 & 2.0 & 1.9 & 1.9 & 1.5 & 1.4 & 1.5 & 1.9 & 1.8 & 1.7 \\
\hline Free state & 9.4 & 8.4 & 6.7 & 6.9 & 4.6 & 4.6 & 5.2 & 4.8 & 4.8 & 7.1 & 6.6 & 6.4 \\
\hline KwaZulu-Natal & 19.7 & 22.5 & 25.5 & 20.3 & 23.7 & 18.9 & 19.9 & 17.9 & 14.3 & 14.1 & 21.2 & 18.7 \\
\hline North-West & 10.8 & 7.2 & 9.1 & 8.2 & 7.2 & 7.2 & 6.8 & 7.4 & 5.2 & 6.3 & 8.4 & 7.2 \\
\hline Gauteng & 2.4 & 11.1 & 8.4 & 19.0 & 17.8 & 30.7 & 27.3 & 39.5 & 42.0 & 39.5 & 15.8 & 27.9 \\
\hline Mpumalanga & 8.8 & 5.7 & 8.4 & 7.4 & 7.8 & 6.4 & 5.3 & 5.3 & 3.6 & 4.7 & 7.3 & 5.9 \\
\hline Limpopo & 17.0 & 16.4 & 14.5 & 13.2 & 13.1 & 8.9 & 11.5 & 4.8 & 6.8 & 3.7 & 13.5 & 9.4 \\
\hline Total & 100.0 & 100.0 & 100.0 & 100.0 & 100.0 & 100.0 & 100.0 & 100.0 & 100.0 & 100.0 & 100.0 & 100.0 \\
\hline
\end{tabular}

Source: IES/OHS 1995.

FIGURE 2

\section{Composition of Household Quintiles by Population Group in 1995 and 2000}

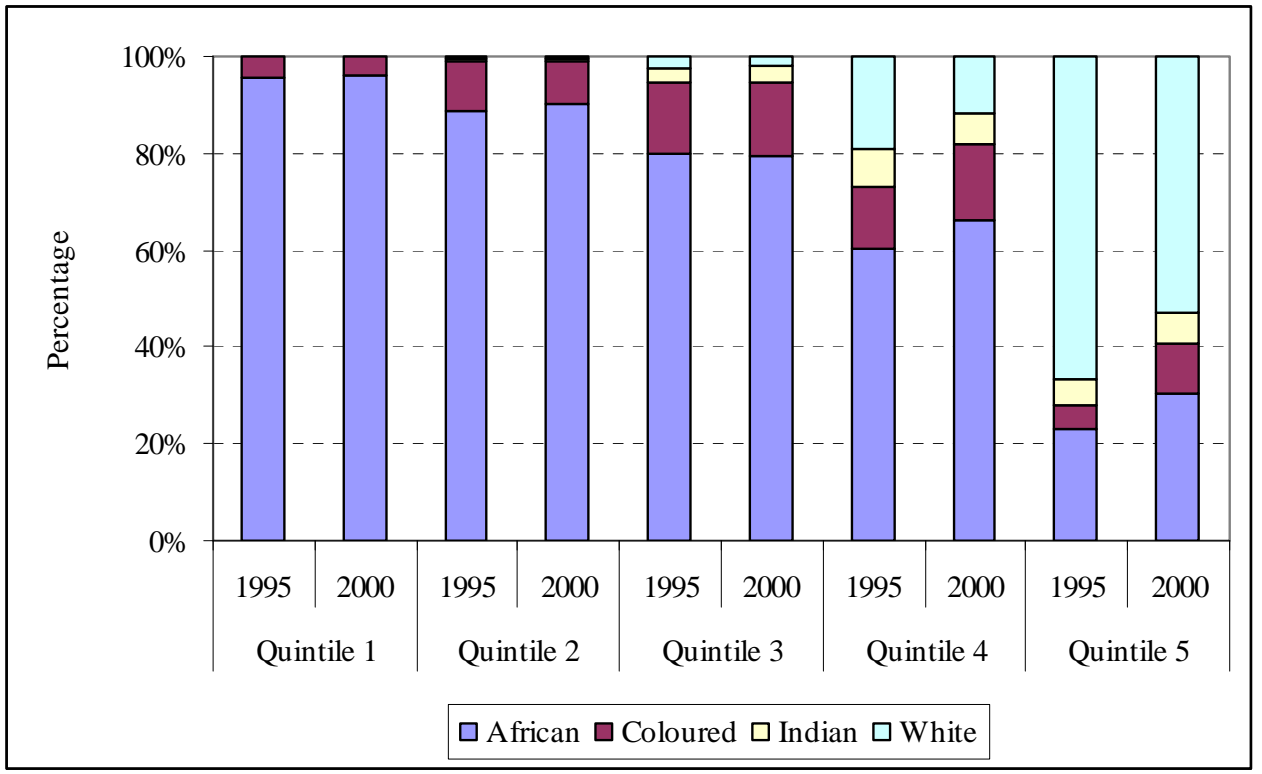

Source: IES/OHS 1995.

Poverty remained concentrated among the African and Coloured population groups in 2000. In fact, more than 95 per cent of the population in the poor quintiles still belonged to these groups. Representation of African and Coloured people in the richest quintile increased from about 28 per cent in 1995 to about 45 per cent in 2000. The share of Whites in quintile five decreased from about 66 per cent in 1995 to about 52 per cent in 2000. This is evidence of an increasing black upper-income class emerging since the fall of apartheid, a phenomenon investigated by Van der Berg et al. (2004) and believed to be one of the main drivers behind growing income inequality in South Africa. 


\subsubsection{Labour Market Participation}

Table 4 shows how labour market characteristics - in particular employment and unemployment rates - varied across the five household quintiles in 1995 and 2000. More precisely, the table shows fractions of workers aged between 15 and 65 years in employment and unemployment (broad and strict definition). Note that these are not unemployment or employment rates. ${ }^{4}$ Not surprisingly, the level of welfare is positively related to the fraction of employed and negatively related to the fraction of unemployed persons, in both 1995 and 2000.

TABLE 4

Labour Market Participation Status by Household Quintiles in 1995 and 2000

\begin{tabular}{|l|r|r|r|r|r|r|r|r|r|r|r|r|}
\hline & \multicolumn{2}{|c|}{ Quintile 1 } & \multicolumn{2}{c|}{ Quintile 2 } & \multicolumn{2}{c|}{ Quintile 3 } & \multicolumn{2}{c|}{ Quintile 4 } & \multicolumn{2}{c|}{ Quintile 5 } & \multicolumn{2}{c|}{ Total } \\
\hline & $\mathbf{1 9 9 5}$ & $\mathbf{2 0 0 0}$ & $\mathbf{1 9 9 5}$ & $\mathbf{2 0 0 0}$ & $\mathbf{1 9 9 5}$ & $\mathbf{2 0 0 0}$ & $\mathbf{1 9 9 5}$ & $\mathbf{2 0 0 0}$ & $\mathbf{1 9 9 5}$ & $\mathbf{2 0 0 0}$ & $\mathbf{1 9 9 5}$ & $\mathbf{2 0 0 0}$ \\
\hline Employed & 17.1 & 21.4 & $\mathbf{2 8 . 7}$ & 33.7 & $\mathbf{4 0 . 6}$ & $\mathbf{4 6 . 7}$ & 54.9 & 59.0 & 68.0 & 72.5 & 38.7 & 43.1 \\
\hline $\begin{array}{l}\text { Unemployed } \\
\text { (expanded) }\end{array}$ & 26.3 & 36.1 & 21.4 & 29.9 & 16.2 & 24.8 & 9.0 & 16.4 & 3.3 & 5.6 & 16.7 & 24.6 \\
\hline Unemployed (strict) & 9.8 & 20.6 & 10.0 & 19.1 & 8.7 & 16.4 & 5.0 & 11.2 & 2.0 & 4.0 & 7.7 & 15.3 \\
\hline Non-participants & 46.8 & 21.93 & 39.9 & 17.41 & 34.5 & 12.14 & 31.1 & 13.46 & 26.7 & 17.9 & 36.9 & 17.09 \\
\hline Total & 100.0 & 100.0 & 100.0 & 100.0 & 100.0 & 100.0 & 100.0 & 100.0 & 100.0 & 100.0 & 100.0 & 100.0 \\
\hline
\end{tabular}

Source: IES/OHS 1995.

Policy implications arising from Table 4 are obvious. The extremely high unemployment rates in South Africa fundamentally impact on welfare levels, hence an increase in employment is likely to benefit the poor. However, the issue of skills constraints (or even of complete lack of skills among the poor) is also at the forefront of policy issues presently faced by South Africa. There is a realisation among policymakers that many of the poor are simply unemployable because they lack certain basic skills demanded by the labour market. This alters the policy stance towards the poverty-unemployment dilemma from one of creating more jobs to one of addressing the lack of skills through training and education. Of course, both job creation and skills training are important policy options. It is especially important to create more low-skilled jobs in order to absorb more of the unskilled unemployed workforce in the meantime, given that education and training policies are inherently longer-term policies.

\subsubsection{Households Income Sources}

The IES and OHS/LFS include a variety of income sources of households and individuals. For analytical purposes, these income sources are aggregated into four main types, namely (1) income from labour, (2) income from business, (3) welfare transfer income, and (4) remittances (household transfers) and other income. Income from labour includes all wages and salaries earned from employment. Business income is very loosely defined as the sum of 'gross operating surplus' (GOS), ${ }_{1}^{5}$ income from dividends, and transfers from incorporated business enterprises. Welfare transfer income in the IES is made up of pensions, disability grants and family allowances. Remittance income is self-explanatory, while 'other income' may include actual or implicit income from home-produced goods, gifts, donations and so on.

Figure 3 shows the income sources of households in 1995 and 2000. Clearly, labour income is an important source of income across the entire spectrum of households, although its importance grows as we move up to the richer household quintiles. This reflects the fact 
that poverty is often associated with large households and high unemployment and, as a result, with a high degree of dependence on a limited number of household members employed in low-income jobs.

\section{FIGURE 3}

\section{Income Sources of All Households, 1995 - 2000}

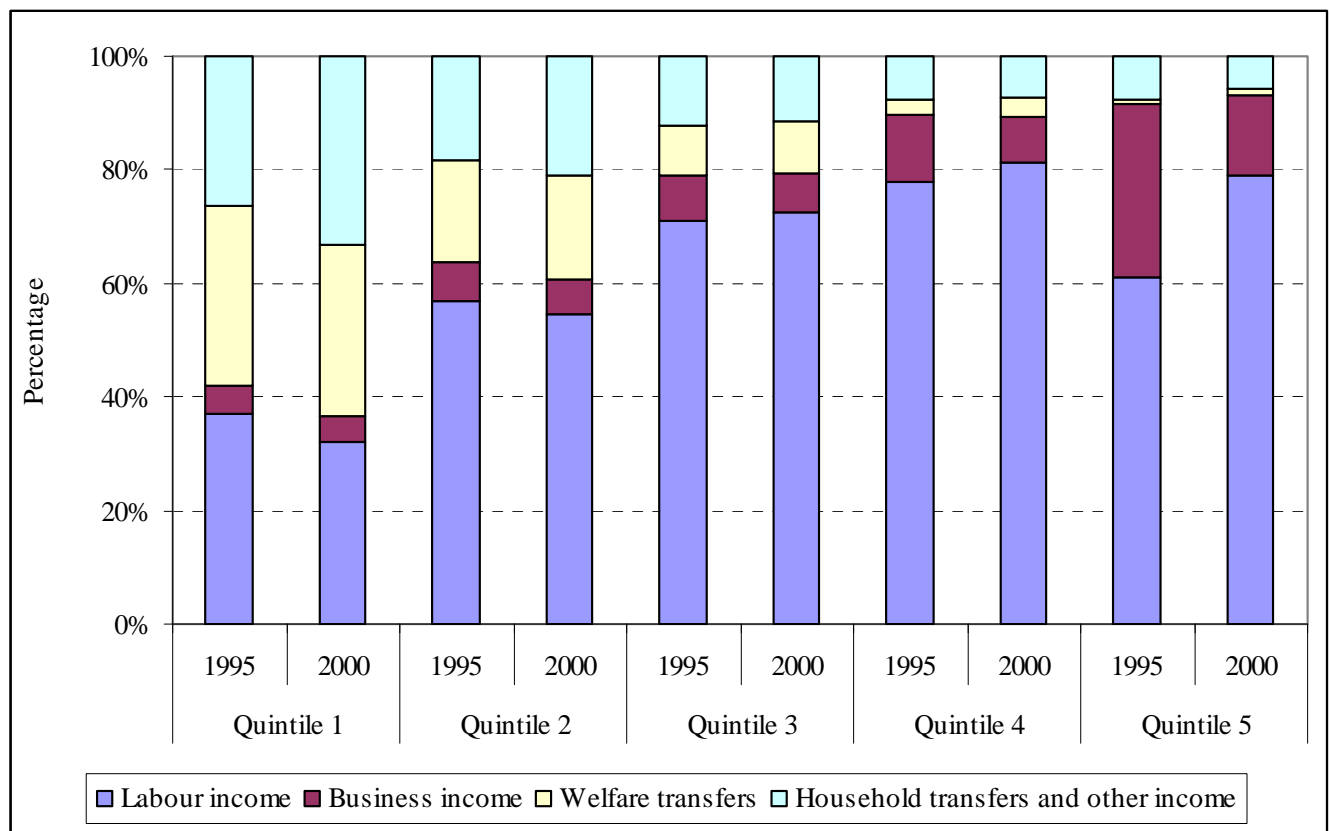

Source: IES/OHS 1995.

Also apparent in Figure 3 is the increasing share taken by business income as we move up to the richer quintiles. It is interesting to note the sharp apparent decline in the relative importance of business income from 1995 to 2000. This certainly has to do with the way in which business income (or GOS in particular) was reported in these two years. Formally, GOS includes income arising from self-employment or 'human capital', which in the 1995 IES was captured under labour income rather than business income (see Pauw, 2005).

Finally, the reliance of poorer households on welfare transfer income and remittances from other households is also apparent. Approximately 22.9 per cent of the income of poor households (quintiles one and two) is earned from welfare transfers, in contrast with only 2.0 per cent of the income of non-poor households. These percentages remained fairly stable between 1995 and 2000, falling just slightly to 22.5 per cent for poor households, while rising to 2.4 per cent for non-poor households.

Next we turn to the income sources of working households in 1995 and 2000 (see Figure 4). Wage income contributed about 80 per cent of household income in 1995, without much variation across the quintiles. This remained the average percentage income share represented by wages in 2000 , although much more variation between quintiles was seen in that year. In particular, the share from total income represented by wages in the lower quintiles dropped significantly. This may be reflecting a number of factors, such as a decline in real wages (see section 3.3), increased unemployment, and the structural change occurring in labour demand 
that adversely affected low-skilled (low-wage) workers (see section 3.3), or an increased diversification of income sources - i.e. more income being derived from non-labour income sources. These possibilities are discussed in more detail in the sections referred to above.

\section{FIGURE 4}

\section{Income Sources of 'Working' Households, 1995 - 2000}

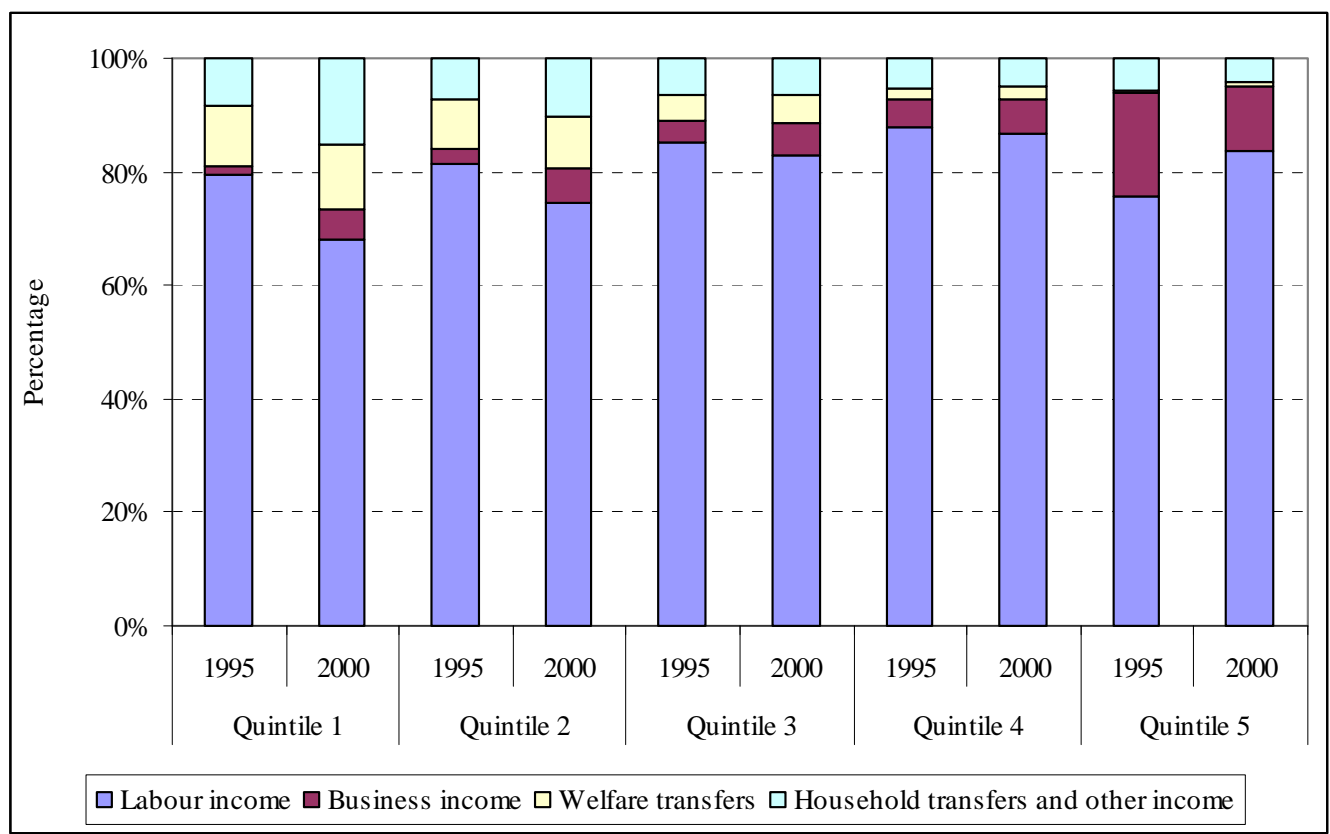

Source: IES/OHS 1995.

Finally, we also explore income sources of households that benefit from welfare transfers. Figure 5 (page 10) includes all households that have had one or more welfare recipients in the household, be these either pensioners or recipients of disability or child grants. These households are clearly very reliant on this source of income, with an average 58.6 per cent of poor and 17.1 per cent of non-poor households' income coming from welfare payments in 1995. These figures changed to 56.7 and 20.6 per cent for poor and non-poor households, respectively, in 2000. South African welfare grants are all means tested, so that, at first glance, it may appear strange to see welfare grant recipients in the non-poor quintiles. However, as shown in Figure 3, such sources usually represent a very small share of overall income among non-poor households in general. Furthermore, the means test is based on the individual recipient's income level (combined with his or her partner in the case of a married couple) and not on the joint household income, which implies that pensioners, for example, living in a non-poor household with their children may in fact receive the pension even if the household is not classified as poor. Finally, the average per capita income in the third quintile was R6 450 in 2000 (see Table 2 - page 4). A single pensioner qualifying for the full pension would have earned R540 per month or R6480 per annum in 2000, thus already placing that person in the third quintile (i.e., non-poor) according to our definition. 
FIGURE 5

Income Sources of 'Welfare Recipient' Households, 1995 - 2000

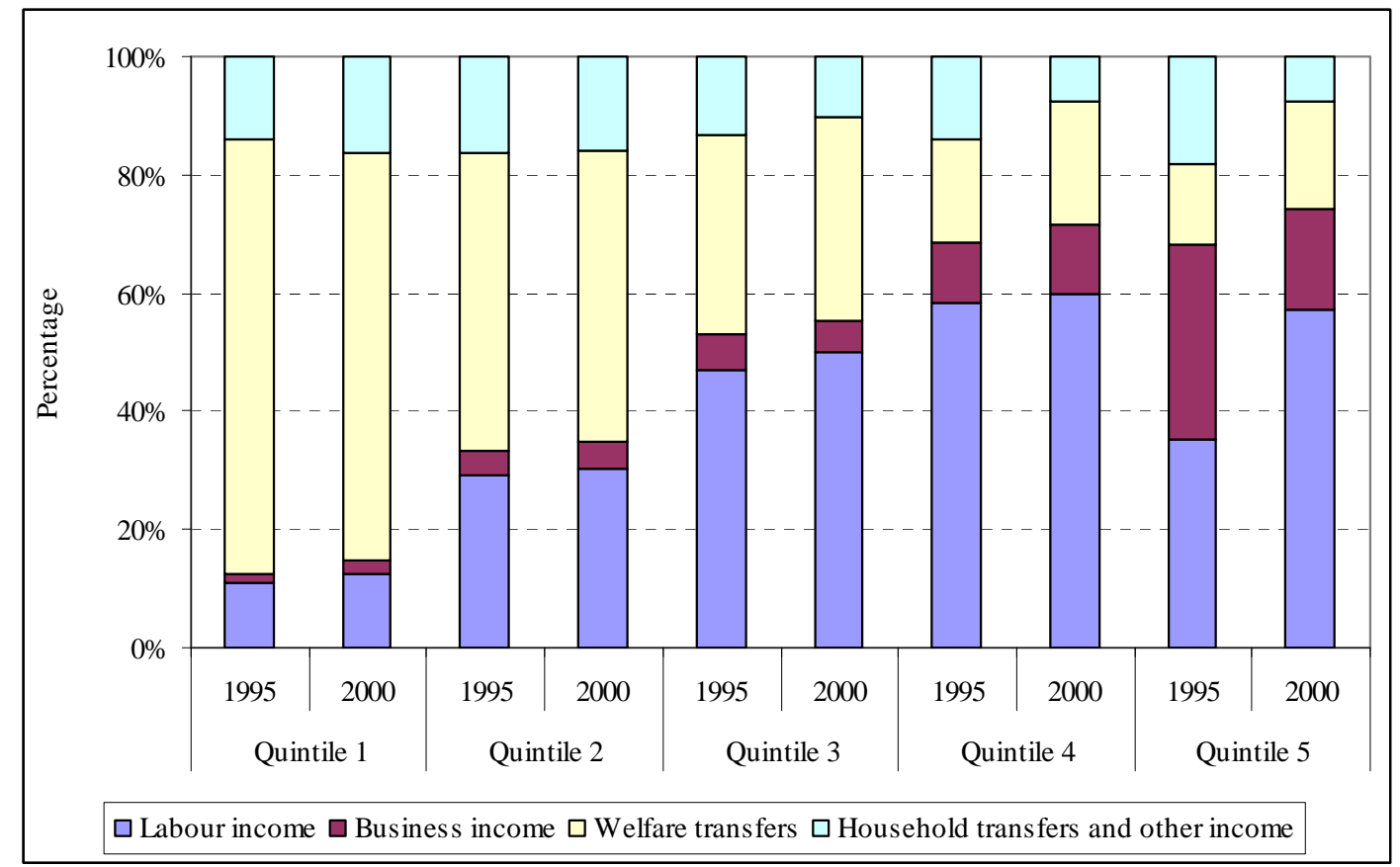

Source: IES/OHS 1995.

Based on estimates of the 1995 and 2000 IES, approximately 29 per cent of the population lived in households that received welfare grants in 1995. This figure increased only marginally to 30 per cent in 2000 - approximately 12.7 million people living in 2.5 million households. Figures from the Department of Social Development suggest that there were just over three million beneficiaries of welfare grants (individuals) in 2000. The question is, however, to what extent do these beneficiaries or the households in which they live actually rely on that welfare transfer income as a source of income. From Figure 5 we learned that low-income households in particular rely heavily on welfare income. In order to analyse the reliance on welfare transfers in a more nuanced way, recipient households (or 'welfare households') are grouped into five categories, respectively indicating those households deriving between zero and 20 per cent, 20 and 40, 60 and 80 and 80 to 100 per cent of their income from welfare transfers.

Figure 6 shows that, in 2000, about 22.8 per cent of recipient households earned between zero and 20 per cent of their total income from such transfers. The percentage of households with higher shares of transfers in total income drops, but then rises sharply for the 80 to 100 per cent group. In fact, in 2000, 29.2 per cent of recipient households earned between 80 and 100 per cent of their income from welfare transfers, the largest of all the income-share cohorts. This share is down slightly from 1995, when 33.2 per cent of recipient households fell into this category. Thus, at least a quarter of all households (or a third of the population) relies on welfare transfers for income, and at least a third of these households earn 80 per cent or more of their income from welfare transfers. 
FIGURE 6

Reliance on Welfare Transfers, 1995 - 2000

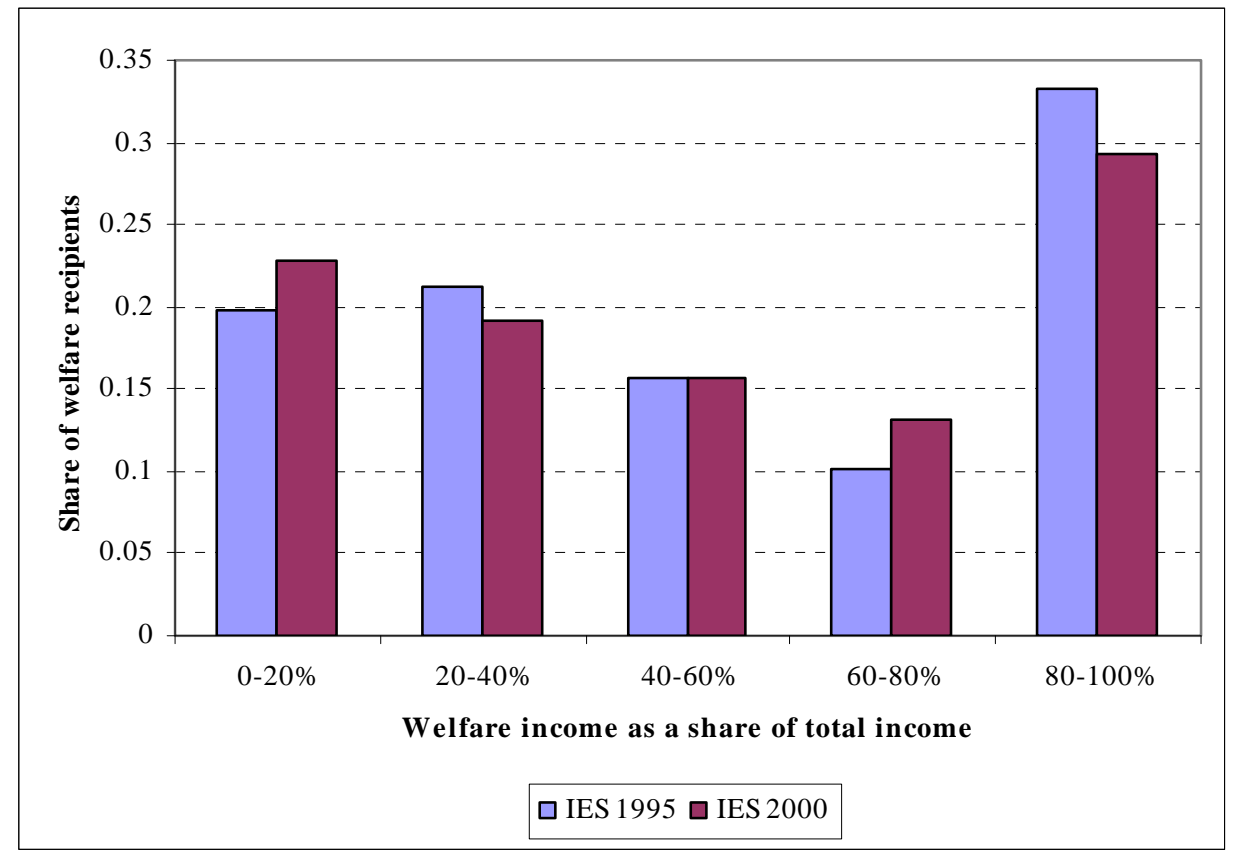

\subsection{POVERTY AND INEQUALITY TRENDS: 1994 - 2006}

The question whether poverty and inequality have improved or worsened during the postapartheid period is topical and even one. Since 2000, various researchers have attempted to analyse trends in poverty and inequality with diverse results, often depending on the measurement approach and/or data sources used. Most poverty and inequality studies conducted in South Africa make use of household surveys released regularly by Statistics South Africa, including the IES (1995 and 2000) and various OHSs and LFSs. Although the income and expenditure data produced by the National Censuses of 1996 and 2001 are limited, these have also been used by some researchers to evaluate changes in income. Very few researchers have attempted to analyse trends beyond 2000 or 2001 , mainly because the LFS datasets have no information on non-wage income and very limited data on household expenditure, while the IES 2005 has not yet been formally released. This section reviews the available data as well as some of the South African literature on poverty and inequality trends since 1994.

\subsubsection{What Do the National Accounts Say?}

Much of the controversy around changes in poverty and inequality over the last decade is caused by the apparent discrepancy between the trends and levels of income and expenditure as reported by Statistics South Africa's various surveys or National Censuses and those reported in the national accounts published by the South African Reserve Bank (SARB). The national accounts data show a steady increase in total current household income between 1990 and 2005. During the period 1995 to 2000, in particular, current income - which is the sum of employee remuneration, property income and transfers (from government, households and the rest of the world) - increased from R555 602 million to R677 570 (2000 prices). Figure 7 (page 12) shows, on the left-hand side, the year-on-year growth in population as well as in current household income between 1991 and 2005. The right-hand side shows the five-year moving averages. During the entire period between 1990 to 2005, real current household 
income grew, on average, at a higher rate than the population did. Furthermore, towards the end of this period the gap between the two growth rates appears to have widened.

FIGURE 7

Real Growth in the Population and in Current Household Income, 1990 - 2005
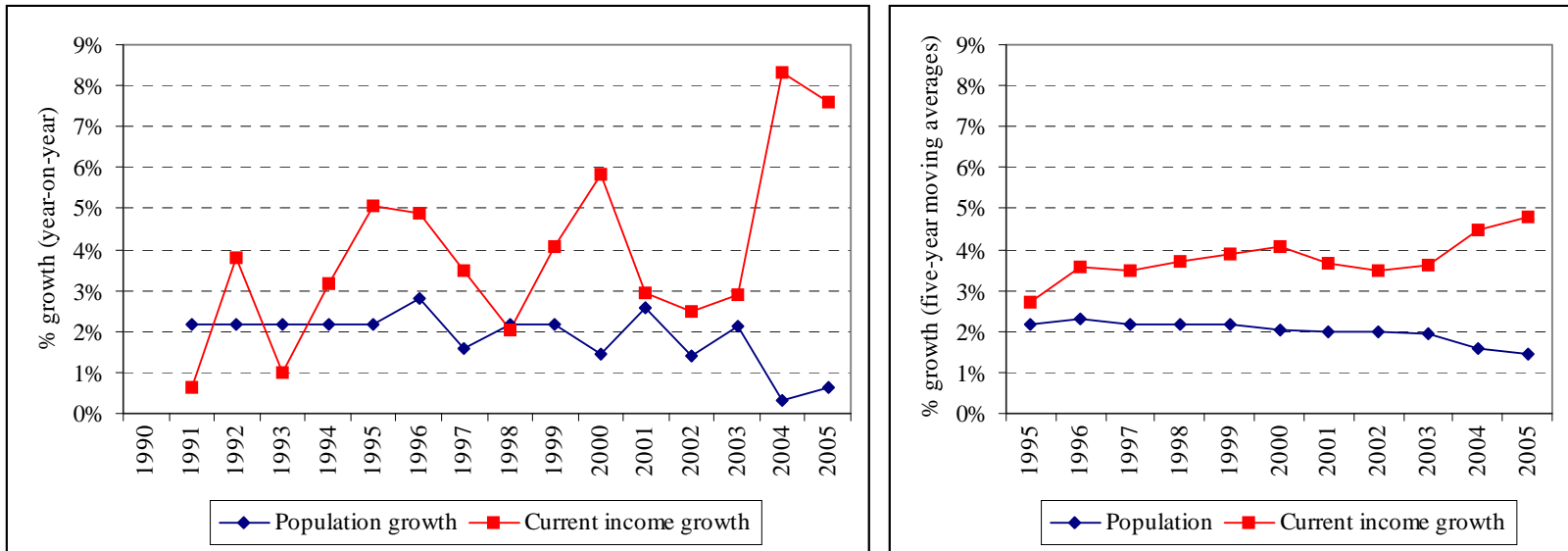

Note: The underlying population series is constructed from Statistics South Africa's mid-year population estimates and various National Censuses (see www.statssa.gov.za).

Source: National Accounts Data, SARB Quarterly Bulletin (2006).

Figure 8 shows the year-on-year and five-year moving average growth in per capita household income as reported in the national accounts. The trend is clear: per capita incomes appear to be growing at an increasing rate (the non-linear curve labelled 'Poly' is a fitted polynomial trend). A comparative indicator of individual welfare levels is the per capita Gross Domestic Product (GDP), which averaged just less than one per cent per annum for the period 1995 to 2000 (see Figure 9). This is yet another indication that South Africans, on average, are better off in real terms in 2005 as compared to 1995, at least as far as the national accounts statistics are concerned.

FIGURE 8

Real Growth in the Per Capita Current Household Income, 1990 - 2005

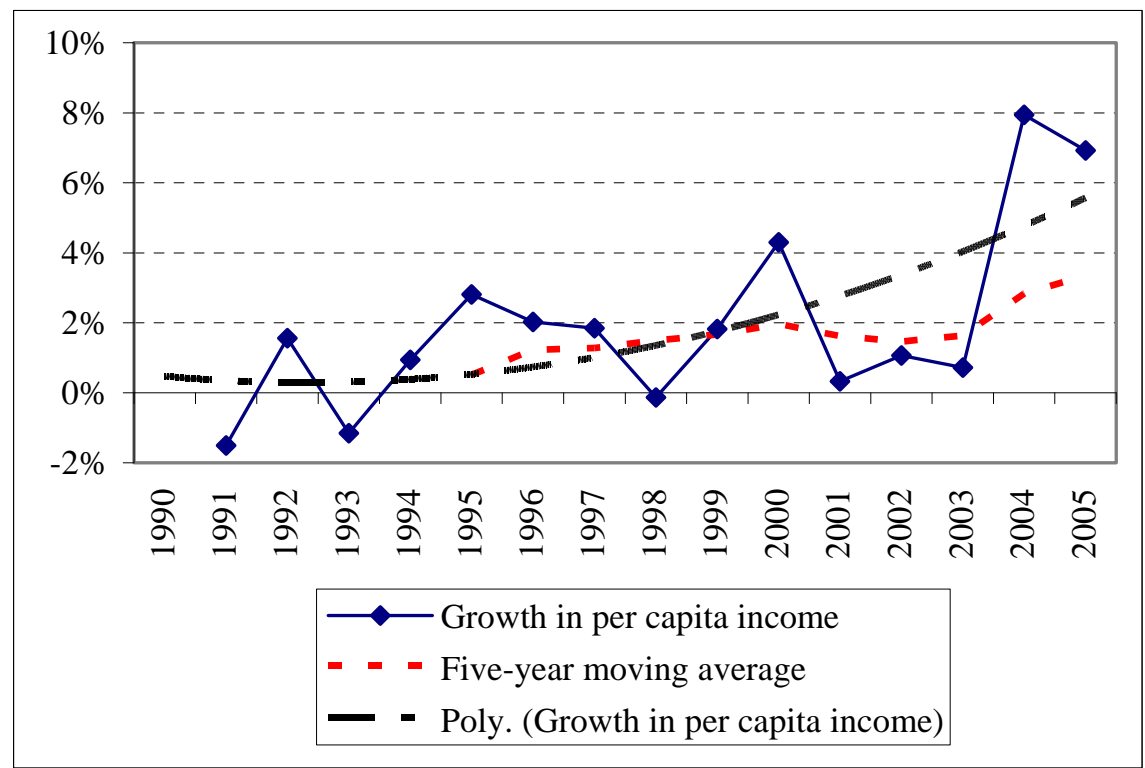

Source: National Accounts Data, SARB Quarterly Bulletin (2006). 
FIGURE 9

Real Growth in the Per Capita GDP, 1990 - 2005

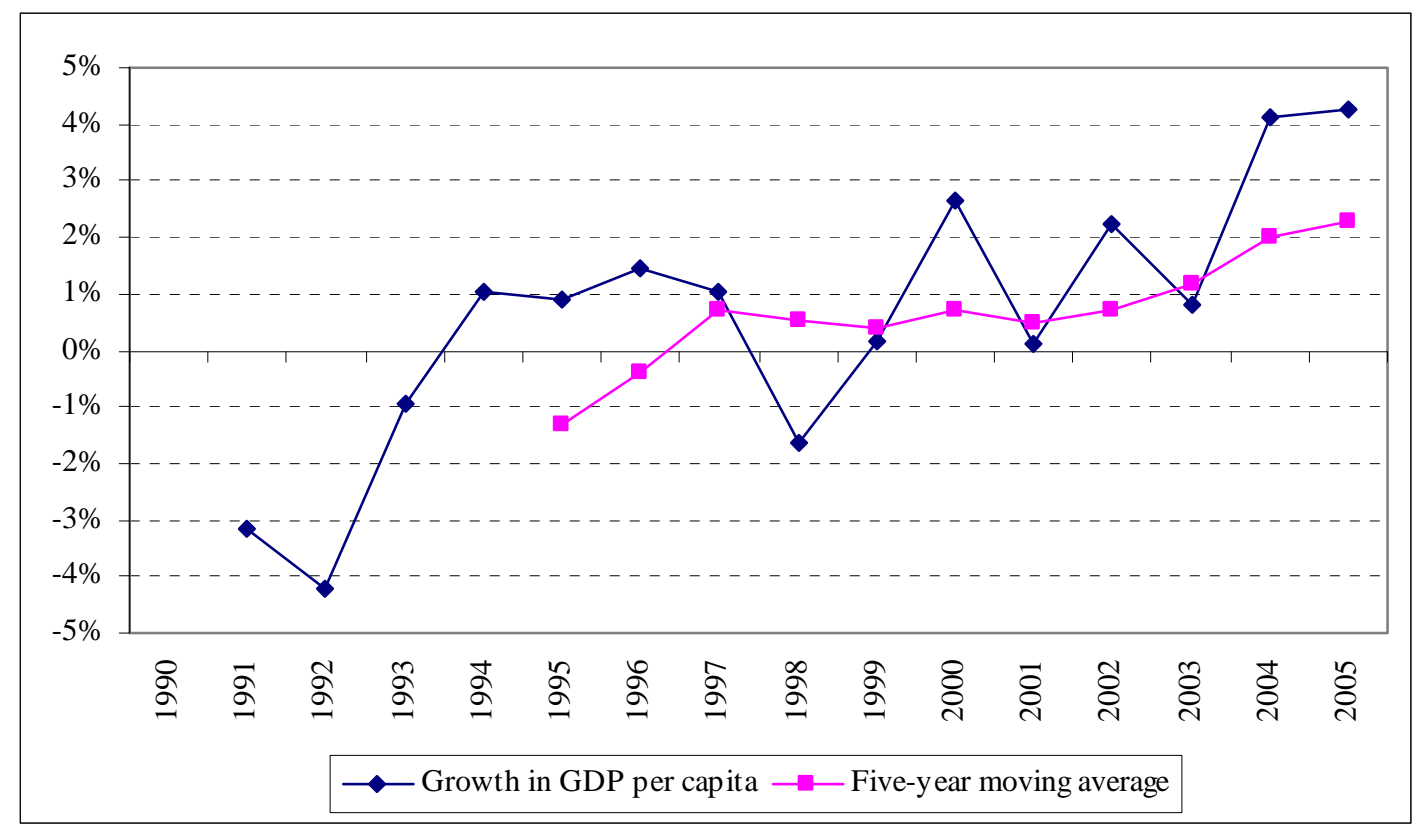

Source: National Accounts Data, SARB Quarterly Bulletin (2006).

\subsubsection{Household Survey Analyses}

In sharp contrast to the SARB's national accounts data, most analyses of the household surveys conducted - in particular those of IES 1995 and 2000 - suggest that there was a decline in average household income between 1995 and 2000. A further cause for concern about the reliability of either the survey data or the national accounts data is that the weighted household income estimates in the surveys do not add up to the national accounts estimates. A variety of factors may contribute to these two fundamental discrepancies. The fact that the weighted survey totals do not match national accounts totals may be due to underreporting in the surveys or incorrect sampling weights. It could of course also imply that the estimates in the national accounts are biased.

Comparability between the IES 1995 and 2000 datasets remains a moot point. These surveys were not conducted as a panel, although sampling designs were similar in the two periods. Some argue that 1995 was an atypical year because the transition of power had just occurred the year before. The IES 2000, however, poses more of a problem. This dataset is fraught with problems, which makes estimates somewhat unreliable and hence comparisons with the 1995 data difficult. Most of those problems relate to sloppiness in data collection, accounting and coding of variables (Van der Berg et al., 2004). There are also numerous records that are problematic due to missing values for some of the variables, while an alarmingly large number of households report zero expenditure on food. As another example, reporting on tax payments is also far below the expected level when compared to actual tax collection data. A detailed account of such problems is included in Pauw (2005). Despite these disheartening shortcomings, the aforementioned IES remains the only and most recent formal account of South African households' income and expenditure estimates. Hence many researchers have persisted in resorting to it for their analyses. 


\section{a) The Statistics South Africa Report}

Shortly after release of the IES 2000, Statistics South Africa issued a report on the changes in household income as measured in the IES of 1995 and 2000 (SSA, 2002). According to that report, the country's average household income - which includes regular income from salaries and wages as well as other sources - was nominally R37 000 in 1995 (equivalent to R51 000 in 2000 prices), in contrast with R45 000 in 2000 (meaning an 11.8 per cent decline, taking into account the adjusted 1995 value). The report also found that average expenditure on goods and services had dropped in 1995 from R51 000 (in 2000 values) to only R40 000 in 2000 (a 21.6 per cent decline). The per capita income declined by 3.1 per cent in real terms, while per capita expenditure dropped by 14.8 per cent. ${ }^{6}$ The report has a limited focus on income poverty, but provides some detail on changes in non-monetary forms of deprivation. As far as inequality is concerned, it indicates that the Gini coefficient increased slightly, from 0.56 to 0.57, between 1995 and 2000 (SSA, 2002).

\section{b) The South African Human Development Report}

In 2003, the United Nations Development Programme published its South Africa Human Development Report (UNDP, 2003). Among other things, the publication reported on changes in poverty and income inequality. The study uses a poverty line of R354 per adult equivalent in 2002 prices, derived on the basis of the cost of a food bundle that would satisfy the basic dietary requirement of an adult. The associated poverty headcount rate was 51.1 per cent in 1995, falling to 48.5 per cent in 2002. ${ }^{7}$ It also compares poverty rates between 1995 and 2002 using the international $\$ 1$ and $\$ 2$ per day poverty lines. At $\$ 2$ per day, the poverty rate declined from 24.2 per cent in 1995 to 23.8 per cent in 2002. However, at \$1 per day - a poverty line often regarded as a measure of extreme poverty - that rate increased from 9.4 per cent to 10.5 per cent between those two years. The report further indicated that inequality as measured by the Gini coefficient had risen from 0.596 in 1995 to 0.635 in 2002 (UNDP, 2003).

\section{c) Hoogeveen and Özler's Study}

Hoogeveen and Özler (2004) analyse changes in poverty using a number of poverty lines, including the $\$ 1$ and $\$ 2$ international poverty lines, as well as a 'lower bound poverty line' of R322 per capita per month (at 2000 prices), which was derived using the cost-of-basic-needs approach. Using the IES 1995 and 2000, they find no change in the poverty rate at the R322 per capita poverty line, but there is evidence that extreme poverty was on the rise. The poverty rate at the $\$ 2$ per day poverty line increased from 32 per cent to 34 per cent, while at the $\$ 1$ poverty line it increased from 7.7 per cent to just over 10 per cent. They also calculate a variety of inequality measures. In particular, they find that the Gini coefficient increased from 0.565 to 0.577 between 1995 and 2000.

\section{d) Authors' Calculations}

Our own calculations of changes in poverty and inequality are based on adjusted versions of the IES 1995 and 2000 datasets. A detailed account of the adjustments made - and of what motivated them - is included in a series of technical reports by Pauw $(2003,2005)$. In short, any visible accounting and reporting inconsistencies were corrected. In the case of IES 2000, food and tax expenditures were inputted to replace unexpected missing or zero values, or cases of obvious underreporting. A further important adjustment made was motivated by a key feature of the IES questionnaire that is often overlooked by researchers. The questionnaire is structured in such a way that the household accounting principle - namely: income ( $Y$ ) equals 
consumption (C) plus savings (S) - should hold for each household in the survey. Reporting was far more accurate in this respect in the IES 1995 than in the IES 2000. In order for this accounting principle to hold, it was assumed that for each household (observation) the larger value for total income and total expenditure was the correct measure, with all the components that make up total income or expenditure being subsequently scaled upwards. This adjustment for each household ensures that the accounting principle also holds for the economy as a whole.

Naturally, the fact that the average discrepancy between total income and expenditure was much higher in the IES 2000 meant that total income and expenditure estimates were scaled up relatively higher in the 2000 dataset. Since no such scaling was done either in the work by Statistics South Africa (SSA, 2002) or by Hoogeveen and Özler (2004), it is of course difficult to compare estimates of poverty and inequality directly by reference to these sources. Furthermore, as shown by Hoogeveen and Özler, estimates may be fairly sensitive to the weights used. The estimates below utilise the 'original' sampling weights distributed with the IES 1995 and 2000 dataset, which differ from Hoogeveen and Özler's preferred set of weights. ${ }^{8}$

In our own analysis, we use an adjusted per capita expenditure variable (assuming a uniform intra-household distribution of income). The 1995 estimates are inflated to 2000 prices using a national CPI price deflator from Statistics South Africa. Table 5 shows that the Foster-Greer-Thorbecke (FGT) poverty headcount ratio $\left(P_{0}\right)$ at the 'lower bound poverty line' of R3 864 per capita per annum increased from 0.451 to 0.521 (namely, from 45.1 per cent to 52.1 per cent). At the $\$ 2$ per day poverty line, the headcount ratio increased by about 50 per cent, from 0.218 to 0.307 , while at the $\$ 1$ per day poverty line it more than doubled from 0.048 to 0.105 . The indication that extreme poverty has risen more rapidly than 'normal' poverty is in accordance with findings by UNDP (2003) and by Hoogeveen and Özler (2004). As shown in Table 5 below, the depth $\left(P_{1}\right)$ and severity $\left(P_{2}\right)$ of poverty also increased over the period at all the poverty lines considered.

TABLE 5

A Comparison of Poverty Estimates Between 1995 and 2000

\begin{tabular}{|l|c|c|c|c|c|c|}
\hline & \multicolumn{2}{|c|}{ US\$1 per day } & \multicolumn{2}{c|}{ US\$2 per day } & \multicolumn{2}{c|}{ R3864 per annum } \\
\hline FGT Poverty Classes & $\mathbf{1 9 9 5}$ & $\mathbf{2 0 0 0}$ & $\mathbf{1 9 9 5}$ & $\mathbf{2 0 0 0}$ & $\mathbf{1 9 9 5}$ & $\mathbf{2 0 0 0}$ \\
\hline Poverty headcount $\left(P_{0}\right)$ & 0.048 & 0.105 & 0.218 & 0.307 & 0.451 & 0.521 \\
\hline Depth of poverty $\left(P_{1}\right)$ & 0.011 & 0.030 & 0.070 & 0.120 & 0.196 & 0.261 \\
\hline Severity of poverty $\left(P_{2}\right)$ & 0.004 & 0.014 & 0.031 & 0.062 & 0.109 & 0.160 \\
\hline
\end{tabular}

Source: Author's calculations using adjusted IES 1995 and 2000 figures.

As far as inequality is concerned, our own estimates are higher than those of other researchers. ${ }^{9}$ However, the trend of rising inequality seems to be a universal finding. The Gini coefficient for the same per capita expenditure measure used for the poverty analysis above increased from 0.622 in 1995 to 0.664 in 2000.

\section{e) Leibbrandt, Levinsohn and McCrary's Study}

Leibbrandt et al. (2005a) compare incomes using the IES/OHS 1995 and IES/LFS 2000 by also inflating the 1995 values to 2000 levels using a national CPI price deflator. Their analysis is limited to individuals aged 18 years and older with 'valid' demographic information and sampling weights, as well as positive income. ${ }^{10}$ Figure 10 and Figure 11 (page 16) show kernel density functions of log real individual income for men and women, respectively, as estimated 
by Leibbrandt et al. (2005a). The authors make three important observations: firstly, there is a clear shift to the left in the distribution, indicating a decline in real incomes. This is evident throughout the distribution, with the exception of the highest income earners. The average fall in incomes is about the same magnitude as the inflation rate, which in practice means that nominal incomes have remained more or less constant, but their real values have been eroded by inflation. Secondly, the shift is more severe for women than it is for men; and thirdly, the large spikes observable in both distributions are caused by old-age pensions, which are a dominant form of income among lower-income individuals, especially for women.

FIGURE 10

Log Real Individual Incomes (Men), 1995 and 2000

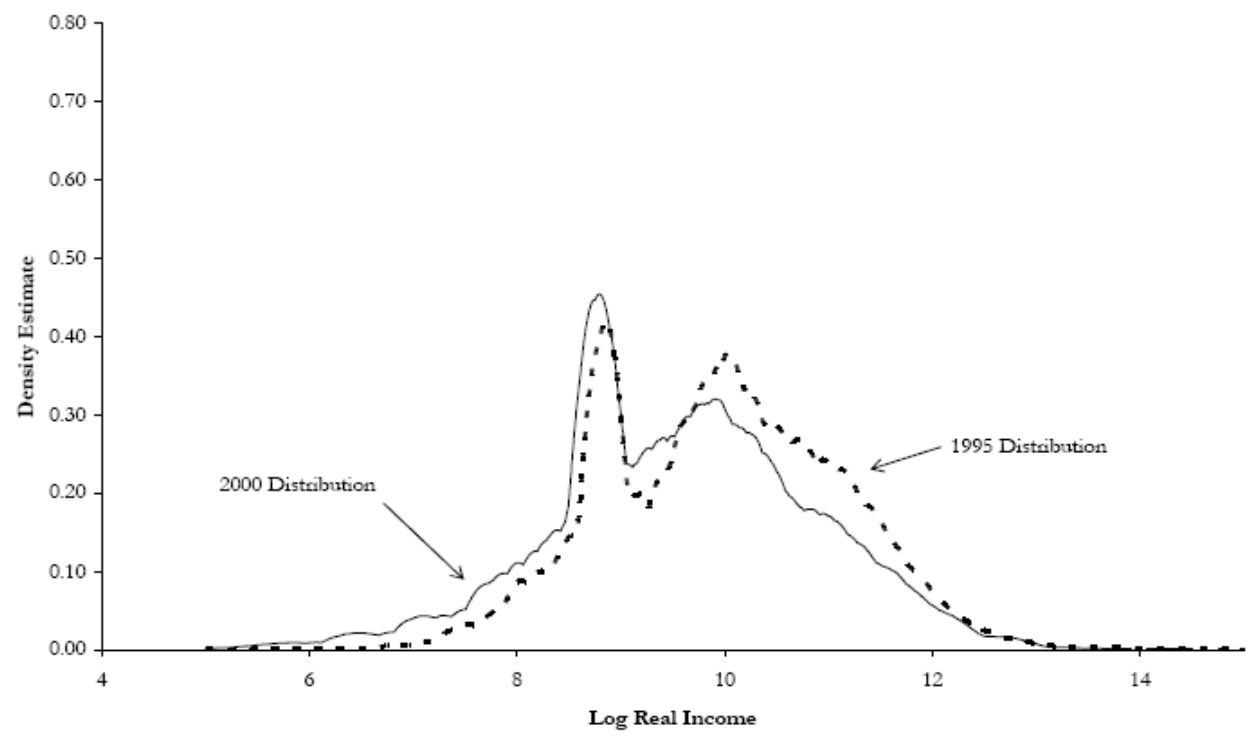

Source: Leibbrandt et al. (2005a); 2000 prices.

FIGURE 11

Log Real Individual Incomes (Women), 1995 and 2000

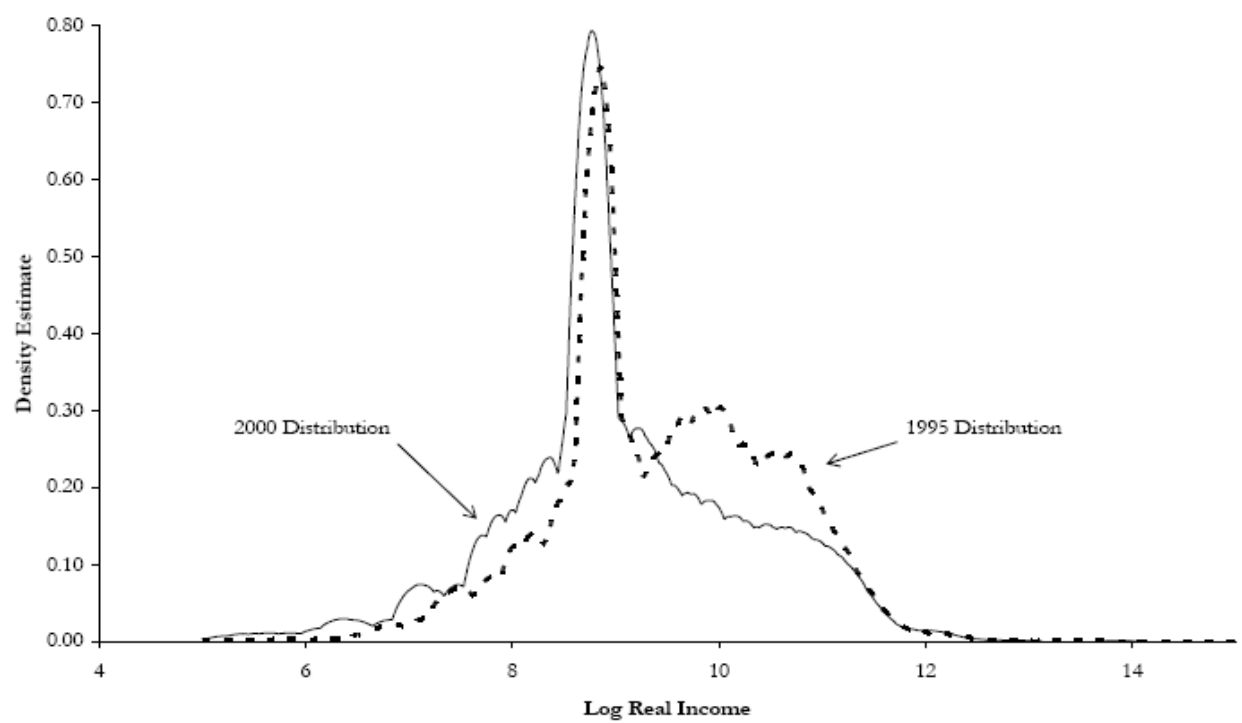

Source: Leibbrandt et al. (2005a); 2000 prices. 
Leibbrandt et al. (2005a) use a variety of methods to find possible reasons for that decline. One hypothesis is that human capital endowments, which are largely determined by education levels, may have declined between the two periods. But this hypothesis is found to be unsubstantiated by the available data. In fact, at worst, education levels remained unchanged, which leads to the conclusion that returns to education declined. This factorthey argue - explains much of the overall decline in individual incomes. This finding is consistent with evidence found elsewhere indicating that young people entering the labour market are becoming better educated and, hence, that the stakes have been raised in terms of finding employment and attracting high wages (see Bhorat and Oosthuizen, 2005; Oosthuizen and Naidoo, 2005).

Another contributing factor could be a selection issue. Two possibilities exist here. Firstly, the IES 1995 and 2000 do not constitute a panel dataset, i.e., the sampled observations are different in the two periods. Even though the sampling was designed to be random and unbiased, differences in selection into the survey sample may explain changes in income. A second issue is selection into the subset of income earners. Leibbrandt et al.'s (2005a) key message is that selection into 'income recipiency' changed between the two periods, thus contributing to the decline seen in average incomes. This is best explained by an example provided in their paper. The authors find that income recipiency rates among White men have declined, whereas they have risen for Black women. Their analysis considers only the subsample of positive income earners. If the incomes of Black women are on average now lower than those of White men, then changes in recipiency rates can explain the decline seen in average incomes.

A final consideration by Leibbrandt et al. (2005a:13) is the 'bad data' argument. Some researchers have argued that the two sets are not comparable (see the earlier discussion), despite the fact that the sampling methods were consistent in the two periods and that the survey was conducted by the same statistical agency. Since this is not a panel, the authors evaluate the mean education levels of various cohorts in the data. Allowing for the fact that different mortality and emigration rates among cohorts may contribute to some differences, they conclude that "the income and expenditure data and accompanying demographic data are reliable" (Leibbrandt et al., 2005a:14). Furthermore, they compare the share of food expenditure between the two periods and find a dramatic shift to the right, which "is entirely consistent with a substantial decline in real income" (2005a:15) (see Figure 12 - page 18).

The food expenditure share argument seems a very plausible one. However, one of the possible explanations for this change, not considered by Leibbrandt et al. (2005a), is relative price changes. If food items are becoming relatively more expensive than non-food items, then households would have to spend a greater share of their budgets on food. Using the South African Reserve Bank data on current and real household expenditure on various commodity items, two price indices are created (see Figure 13 - page 18). The growth in prices of items other than food was fairly stable between 1995 and 2000, averaging about 8.1 per cent. Growth of food prices, by contrast, although much more volatile, averaged around 7.2 per cent between 1995 and 2000. Comparative figures from the Statistics South Africa website ${ }^{11}$ put the average growth in the food expenditure $\mathrm{CPI}$ at 6.9 per cent for the same period, in contrast with the overall CPI index growth of 6.7 per cent. Thus, there is no conclusive evidence that food prices grew more rapidly than other prices, at least not to the extent that this effect would have significantly altered the food share of overall household expenditure. This adds weight to the conclusion drawn by Leibbrandt et al. (2005a). 
FIGURE 12

Food Share of Household Expenditures, 1995 and 2000

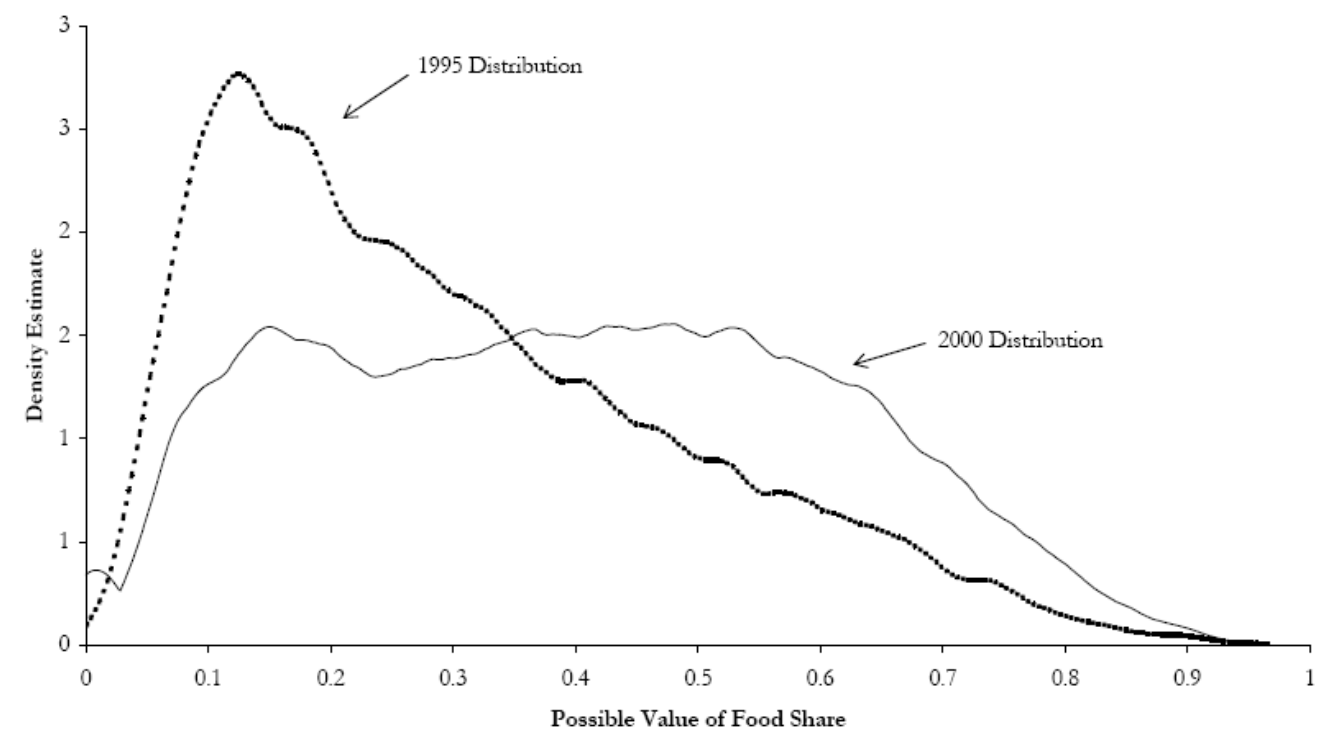

Source: Leibbrandt et al. (2005a).

FIGURE 13

Relative Growth in Prices, 1990 - 2005

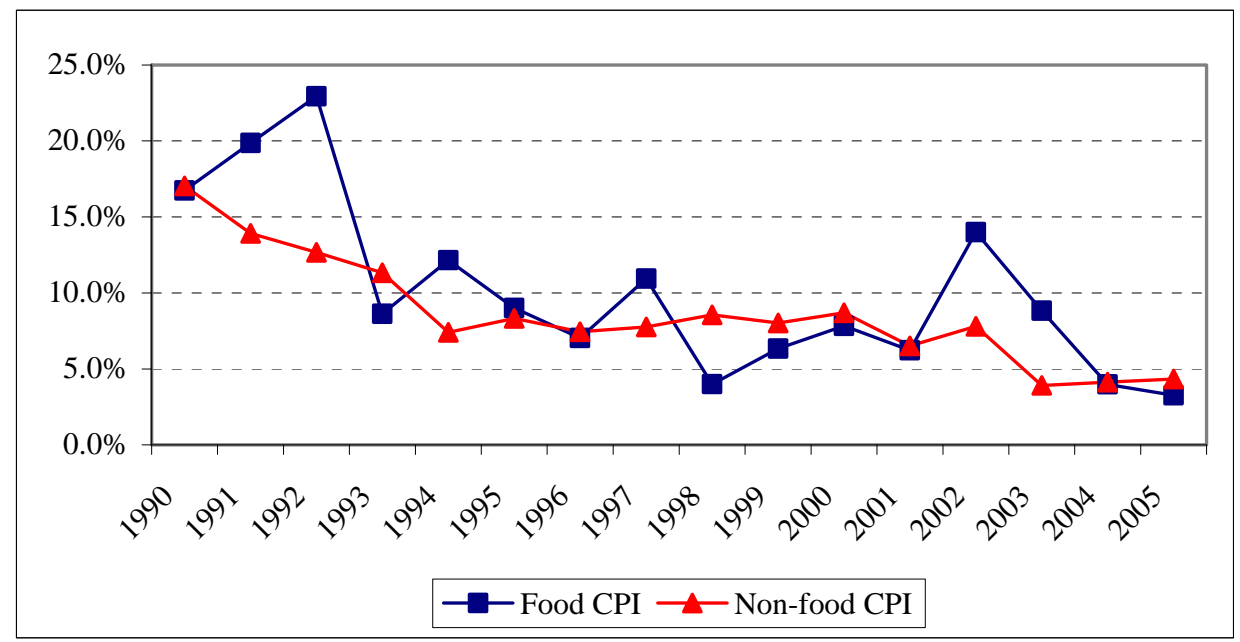

Source: Authors' calculations, using National Accounts Data, SARB Quarterly Bulletin (2006).

f) Leibbrandt, Poswell, Naidoo, Welch and Woolard's Study: National Census Data

A study by Leibbrandt et al. (2005b) utilises the South African National Censuses of 1996 and 2001 to evaluate changes in poverty and inequality. Much of the paper is devoted to changes in non-income poverty and inequality, i.e., 'access-based measurement approaches'. Such an approach focuses on households' type of dwelling, access to water, energy sources, sanitation and other basic services. The authors report 'significant improvements' in these access measures between 1996 and 2001, much of which can be attributed to substantial investments by government in public service provisioning, especially in previously disadvantaged communities. 
In order to evaluate income measures of poverty and inequality, Leibbrandt et al. (2005b) had to deal with a number of data-related issues. Firstly, personal income is reported in terms of income bands rather than of actual levels. The bands used in 1996 and 2001 are not comparable. In particular, the top income band in 1996 (R30 000 or more) was lower, in real terms, than the top three income bands in 2001. This meant that these three latter bands had to be compressed. This affects inequality measurement. Secondly, when aggregating personal incomes at household level, the authors find many households with missing values or zero income ( 23 and 28 per cent of observations in 1996 and 2001, respectively). These households are then excluded from the income poverty and inequality analyses. However, since at least some of these households may truly be zero-earners, just dropping these observations may also have an impact on poverty and inequality measures. ${ }^{12}$

A kernel density plot of log per capita incomes reveals some evidence of a leftward shift in income distribution between 1996 and 2001 - a shift that is "particularly pronounced in the middle and lower-income section s the distribution" (Leibbrandt et al., 2005b). Much of this shift occurred within the region of two poverty lines used by the authors, namely, the $\$ 2$ per day poverty line and the R250 per capita per month reference line (1996 prices). The authors calculate that the poverty headcount rises from 0.26 to 0.28 at the $\$ 2$ per day poverty line, and from 0.50 to 0.55 at the R250 poverty line. However, the poverty gap ratio remains unchanged at the $\$ 2$ poverty line, while increasing only marginally from 0.30 to 0.32 at the R250 poverty line.

As far as inequality is concerned, Leibbrandt et al. (2005b) find that the Gini coefficient for all population groups has increased, with the national Gini coefficient increasing from 0.68 to 0.73 between 1996 and 2001. They also analyse changes in inequality within and between population groups by decomposing the Theil index of inequality, and find that the share of between-group inequality in overall inequality decreased between 1996 and 2000, a result also confirmed by the Hoogeveen and Özler (2004) study.

\section{g) Van der Berg and Louw's Study: Adjustments to the IES Data}

Van der Berg and Louw (2004) compare South African poverty and inequality trends between 1970 and $2000 .{ }^{13}$ The authors argue that the poor quality of the available household survey data, and especially of the IES 2000, calls for substantial data adjustments to be made. The fact that the household survey data is incompatible with the national accounts data is one of their major concerns.

In short, their technique involves using time-series national-accounts income data as the benchmark, broken down into three components (remuneration, government transfers and property income). The between-race distribution of each income component in each year is then estimated by reference to a variety of sources. Total remuneration data are obtained from average wage and employment data, by race, from the Standardised Employment Series, ${ }^{14}$ as well as the OHSs and LFSs. Transfer income data are obtained from the Department of Social Development, while property income is derived from intermittent surveys conducted by the Bureau of Market Research (BMR). The within-group income distributions are obtained from a variety of sources, including the BMR, the urban foundation and the 1995 and 2000 IESs, respectively linked to the OHS and LFS. Rather than using the survey means, the previously derived inter-racial group means are used, i.e., survey data are effectively scaled up or down to match the inter-racial group means which, in turn, are consistent with the national averages as 
reported in the national accounts. The authors admit that the crucial assumption of such an approach is that the distribution of income obtained from these alternative data sources is correct, but that the averages or weighted totals are not. It further assumes that the aggregate figures reported in the national accounts are correct.

Their results show that there were small increases in income inequality within all racial groups between 1995 and 2000. In particular, the Gini coefficient rose from 0.57 to 0.59 for Africans, from 0.52 to 0.55 for Coloureds, from 0.49 to 0.51 for Indians and from 0.47 to 0.49 for Whites. An estimate of national inequality is omitted. As far as poverty estimates are concerned, Van der Berg and Louw (2004) report 'pessimistic' and 'optimistic' estimates for 2000, the latter based on higher employment estimates for the post-1995 period. Using a poverty line of R3,000 (2000 prices), they find that overall poverty decreased from 38.8 to 38.6 per cent under the pessimistic scenario, and to 36.4 per cent under the optimistic scenario. The number of poor people increased, however, because of population growth.

\section{h) Van der Berg, Burger, Burger, Louw and Yu: Using Alternative Income Data}

Few studies have attempted to analyse the period beyond 2000 or 2001 . One such study by Van der Berg et al. (2005) has attracted some attention. This paper, in a sense, builds further on the methods developed by Van der Berg and Louw (2004), but utilises the All Media Products Surveys (AMPS) conducted by the South African Advertising Research Foundation as the source of income data, rather than the IESs. As far as inequality results are concerned, the most surprising result from their analysis is the declining inequality (as measured by the Gini coefficient) within the Black population since 2000.

However, the main aim of their study is to evaluate poverty trends. In line with most other such studies, they find that the proportion of people living in poverty increased between 1993 and 2000. Since 2000, this trend has been reversed, thanks largely - according to Van der Berg et al. (2005), to favourable economic growth and employment creation, coupled with large-scale expansion of the social grant system. Using a poverty line of R3 000 per annum, they find that the headcount ratio $\left(P_{0}\right)$ first increased from 0.406 in 1993 to 0.413 in 2000, but declined steeply thereafter to reach 0.332 in 2004.

The poverty gap ratio $\left(P_{1}\right)$ and the poverty gap squared $\left(P_{2}\right)$ also show relatively large declines for the period 2000 to 2004, which is a reflection of their finding that the per capita incomes of those individuals in the poorest two income quintiles rose by more than 30 per cent during the period. Not only did the headcount ratio decline, but also the absolute number of poor people dropped from 18.5 million in 2000 to 15.4 million in 2004, despite the overall population growth of about 3.8 per cent during the period. The authors maintain that these are their conservative estimates, and that the "true conclusion regarding the extent of poverty in South African may be even more optimistic than the one drawn" in their study (Van der Berg et al., 2005:22).

i) Meth's Critique of Van der Berg et al.

In a recent paper, Meth (2006) challenges the Van der Berg et al. (2005) findings. He first points out at a number of inconsistencies with regards to the poverty headcount ratios and the associated poverty headcounts: the numbers presented do not seem to produce plausible population estimates. That aside, most of the paper focuses on discrediting Van der Berg et al.'s 
poverty estimates for 2004 by comparing them with his own estimates derived from the LFS 2004. The LFSs remain an interesting choice for poverty analysis but are perhaps not as well suited as the IES. Only a single household-level expenditure estimate is reported by respondents by selecting an appropriate expenditure band or bracket, which implies that the distribution is discontinuous. Meth (2006) adjusts expenditures upward in cases where the reported household income exceeds the reported expenditure level. A concern of this approach is, of course, the fact that the LFS is largely a labour force survey and reports in detail only on wages and salaries. There is limited information on welfare transfer income, and no information on other income sources such as remittances or investment income.

Meth (2006) suggests that Van der Berg et al.'s (2005) poverty headcounts are too low, arguing that, based on his estimates, between 18 and 20 million people live in poverty and not 15.4 million people as estimated by Van der Berg et al. (2005). This - he argues further - has important implications for poverty reduction: "it matters very much ... whether there are 15 million people below the poverty line, or 20 million". Moreover, "the chances of meeting the poverty-halving goal to which the government has committed itself are considerably diminished if there turn out to be many more people to be raised out of poverty" (Meth, 2006:6). Meth also calculates significantly higher values for the poverty gap ratio $\left(P_{1}\right)$. In fact, he finds that, in order to close the poverty gap, it would cost between R2 and R6 billion more than what Van der Berg et al.'s (2005) estimates suggest.

One of the assumptions underlying the justification for scaling survey income and expenditure estimates to the level of the national accounts data is that respondents often underreport their true incomes and expenditures in the surveys. ${ }^{15}$ Meth (2006) allows for different degrees of underreporting in his poverty estimates and shows that his results only start to replicate those of Van der Berg et al. (2005) when he allows for between 38 and 50 per cent underreporting. He then argues that since welfare transfers are fixed by government, the only possible component of total household income that can be assumed as underreported is income from the employed (either from those within the household or from remittances of household members employed elsewhere). This implies that, if expenditure is underreported by, say, 38 per cent, then the effective or actual error on earned income is 85 per cent in the bottom expenditure category (R0 - R399). The average effective underreporting for the R0 - R2 499 category is 54 per cent and so on. Meth (2006) argues that this is implausible, and concludes that Van der Berg at al.'s (2005) method overcorrects underreporting, especially at the bottom end of income distribution.

As mentioned previously, Van der Berg at al. (2005) attribute the sharp decline seen in poverty to improved employment conditions, but largely ascribe it to the rapid increase achieved in welfare transfer payments - more than a 70 per cent increase in real terms during the last four years. Meth (2006) agrees that this would undoubtedly have had an important impact, but also notes an important budgetary consideration in this regard, which has led to the "state's strong antipathy to the extension of the social grant system beyond its present boundaries". The trend towards rapidly growing coverage of grants is unlikely to continue, hence extrapolations on the current trend are nonsensical (Meth, 2006:54). 


\subsubsection{Summary}

The preceding discussion raises a number of questions about survey data and national accounts data in South Africa. Should one trust the national accounts data as the benchmark and adjust survey data aggregates accordingly? Or should one perhaps accept that national accounts data may also be inaccurate? Leibbrandt et al. (2005a:8) note, firstly, that these types of discrepancies (between household survey data and national accounts) are not uncommon, and secondly, that the "results using the survey data are replicable and all the inputs - principally survey responses and sampling weights - are explicit and available, hence yielding a relatively transparent and replicable methodology".

Furthermore, national accounts data are frequently revised. Therefore, any given dataset, even if it is currently a final release, may still be subject to future revisions. In a recent study by Van Walbeek (2006), the issue of revisions in South African national accounts data is investigated. With regards to GDP, consumption expenditure and disposable income of households, Van Walbeek notes that revisions made have had a "significant positive bias [on estimates] especially after 1994". Consequently, magnitudes and trends are affected by the vintage of the data.

Data problems aside, there seems to be consensus that inequality in the distribution of income has increased during the last decade. On the issue of whether per capita incomes have increased, though, and, more importantly, of whether the poverty rate has declined, there is a great deal of disagreement. Table 6 summarises the results presented in this section. Not only are changes in poverty estimates sensitive to the choice of poverty line (see, for example, the SSA 2002 and UNDP 2003 studies), but they are also sensitive to the sampling weights used. Since the release of the IES 2000, a number of weights have been distributed officially and unofficially, and there seems to be no clear indication from Statistics South Africa about which set of weights is the right one. It also seems that it is only possible to achieve a result indicating a reduction in poverty once substantial adjustments are made to the traditional household surveys (Van der Berg and Louw, 2004) or when alternative datasets that are perhaps less suited for this type of analysis (e.g., the AMPS data used by Van der Berg et al. [2005] ) are used.

Looking at the evidence presented by Van der Berg et al. (2005), which shows an initial increase in the poverty rate between 1995 and 2000 (which is consistent with most of the other studies on the matter) and a subsequent decline in poverty between 2000 and 2004, one is tempted to agree that this sounds realistic. Unemployment trends since 2000 suggest a turnaround in job losses after 2002 (DPRU, 2006). Welfare grants have been stepped up significantly since 2000 , and economic growth has been favourable. The critique by Meth (2006) uses as its main data source the LFS 2004 - a survey in which incomes and expenditures are poorly reported. Hopefully, the eagerly awaited IES 2005 will shed some light on these issues. 
TABLE 6

Summary of Income, Poverty and Inequality Findings

\begin{tabular}{|c|c|c|c|c|c|c|c|}
\hline & Income & Details & Poverty & Details & Inequality & Details & Data \\
\hline SSA (2002) & $\downarrow$ & $\begin{array}{l}\text { Average household income declined by } 11.8 \text { per } \\
\text { cent; per capita income by } 3.1 \text { per cent. }\end{array}$ & - & - & $\uparrow$ & $\begin{array}{l}\text { Gini coefficient increased from } 0.56 \\
\text { to } 0.57 \text { between } 1995 \text { and } 2000 .\end{array}$ & IES 1995, 2000 \\
\hline UNDP (2003) & & & $\downarrow / \uparrow$ & $\begin{array}{l}\text { Depending on poverty line: National food } \\
\text { poverty line shows decline in poverty from } \\
51.1 \text { per cent to } 48.5 \text { per cent between } 1995 \\
\text { and } 2002 \text {. Also decline for } \$ 2 \text { per day, but } \\
\text { increase from } 9.4 \text { per cent to } 10.5 \text { per cent } \\
\text { for } \$ 1 \text { per day extreme poverty line. }\end{array}$ & $\uparrow$ & $\begin{array}{l}\text { Gini coefficient increased from } \\
0.596 \text { to } 0.635 \text { between } 1995 \text { and } \\
2002 \text {. }\end{array}$ & IES 1995 \\
\hline $\begin{array}{l}\text { Hoogeveen \& } \\
\text { Özler (2004) }\end{array}$ & - & - & $\uparrow / \rightarrow$ & $\begin{array}{l}\text { Depending on poverty line: For } \$ 2 \text { per day } \\
\text { poverty line poverty increases from } 32 \text { per } \\
\text { cent to } 34 \text { per cent between } 1995 \text { and } 2000 \text {, } \\
\text { while for the 'lower bound poverty line' it } \\
\text { remains virtually unchanged at } 58 \text { per cent. }\end{array}$ & $\uparrow$ & $\begin{array}{l}\text { Gini coefficient increased from } \\
0.565 \text { to } 0.577 \text { between } 1995 \text { and } \\
2000 \text {. The mean log deviation and } \\
\text { Theil index also show increases in } \\
\text { inequality. }\end{array}$ & IES 1995, 2000 \\
\hline $\begin{array}{l}\text { Own } \\
\text { calculations }\end{array}$ & $\downarrow / \uparrow$ & $\begin{array}{l}\text { Disposable income of the poor declined by } 10.1 \\
\text { per cent, while that of the non-poor increased by } \\
9.8 \text { per cent. Overall disposable income declined } \\
\text { by } 5.4 \text { per cent. }\end{array}$ & $\uparrow$ & $\begin{array}{l}\text { Increased at all the poverty lines evaluated, } \\
\text { in particular from } 45.1 \text { to } 52.1 \text { per cent using } \\
\text { Hoogeveen and Özler's R3 } 864 \text { per capita } \\
\text { per annum poverty line. }\end{array}$ & $\uparrow$ & $\begin{array}{l}\text { Gini coefficient increased from } \\
0.622 \text { to } 0.664 \text { between } 1995 \text { and } \\
2000 \text {. }\end{array}$ & IES 1995, 2000 \\
\hline $\begin{array}{l}\text { Leibbrandt et } \\
\text { al. (2005a) }\end{array}$ & $\downarrow$ & $\begin{array}{l}\text { Average fall in incomes by roughly the same } \\
\text { magnitude as inflation. }\end{array}$ & - & - & - & - & IES 1995, 2000 \\
\hline $\begin{array}{l}\text { Leibbrandt et } \\
\text { al. (2005b) }\end{array}$ & $\downarrow$ & $\begin{array}{l}\text { Leftward shift in the entire income distribution, } \\
\text { particularly pronounced in the middle- to lower } \\
\text { sections of the distribution. }\end{array}$ & $\uparrow$ & $\begin{array}{l}\text { Poverty increased from } 26 \text { to } 28 \text { per cent at } \\
\text { the } \$ 2 \text { per day poverty line, and from } 50 \text { to } \\
55 \text { per cent at the R250 per capita per } \\
\text { month poverty line }\end{array}$ & $\uparrow$ & $\begin{array}{l}\text { Gini coefficient increased from } 0.68 \\
\text { to } 0.73 \text { between } 1995 \text { and } 2000 .\end{array}$ & $\begin{array}{l}\text { Census } 1996 \text { and } \\
2001\end{array}$ \\
\hline $\begin{array}{l}\text { Van der Berg } \\
\text { and Louw } \\
(2004)\end{array}$ & - & - & $\downarrow$ & $\begin{array}{l}\text { Falls under both the 'pessimistic' and } \\
\text { 'optimistic' scenarios, from } 38.8 \text { per cent in } \\
1995 \text { to } 38.6 \text { or } 36.4 \text { per cent in } 2000 \text {, at a } \\
\text { poverty line of R3 } 000 \text { per capita per annum. }\end{array}$ & $\uparrow$ & $\begin{array}{l}\text { Increases in inequality within all } \\
\text { racial groups, namely } 0.57 \text { to } 0.59 \\
\text { for Africans, } 0.52 \text { to } 0.55 \text { for } \\
\text { Coloureds, } 0.49 \text { to } 0.51 \text { for Indians } \\
\text { and } 0.47 \text { to } 0.49 \text { for Whites. } \\
\end{array}$ & $\begin{array}{l}\text { Standard Employment } \\
\text { Series, OHS, LFS, } \\
\text { IES (various years) }\end{array}$ \\
\hline $\begin{array}{l}\text { Van der Berg } \\
\text { et al. (2005) }\end{array}$ & - & - & $\uparrow / \downarrow$ & $\begin{array}{l}\text { Initially increased from } 40.6 \text { per cent in } 1993 \\
\text { to } 41.3 \text { per cent in } 2000 \text {, but thereafter } \\
\text { declined to } 33.2 \text { per cent in } 2004 \text {, at a } \\
\text { poverty line of R3 } 000 \text { per capita per annum. }\end{array}$ & - & - & $\begin{array}{l}\text { Standard Employment } \\
\text { Series, OHS, LFS, All } \\
\text { Media Products } \\
\text { Surveys (various } \\
\text { years) }\end{array}$ \\
\hline
\end{tabular}




\section{PRO-POOR GROWTH AND SOUTH AFRICA'S EMPLOYMENT TRACK RECORD}

\subsection{SOUTH AFRICA'S MACROECONOMIC POLICIES SINCE $1994^{16}$}

The first comprehensive macroeconomic strategy adopted by the newly elected government in 1994 was the Reconstruction and Development Programme (RDP). The RDP was committed to reducing poverty and inequality "with its underpinning ideology acknowledging the links between development, growth, reconstruction and development" (Bhorat et al., 2005:2). The policy placed government-funded infrastructural development at the centre. However, given budgetary constraints, it was proposed that rather than increasing total expenditure, the composition of expenditure be shifted towards more capital spending.

The Growth, Employment and Redistribution (GEAR) strategy replaced the RDP in 1996 and had an implementation period of four years. Whereas the RDP focused on growth through (infrastructural) development led by government, GEAR envisaged a more central role for the private sector. Although the RDP was certainly successful in bringing about stability and moderate economic growth (an average of three per cent per annum was achieved between 1994 and 1996), the advocates of GEAR felt that higher growth was crucial. Policymakers envisaged "sustained growth on a higher plane", achieved through increased private sector investments and an outward-oriented manufacturing sector, as one of the main outcomes of GEAR (Department of Finance, 1996). Although the optimistic predictions of GDP growth around six per cent by 2000 never quite materialised, the economy performed reasonably well in an unstable international environment.

An outcome of improved economic growth, so the GEAR policymakers propagated, would be rapid job creation. Policymakers predicted that an average of 270,000 jobs would be created every year between 1996 and 2000, which translates into an average annual increase of 2.7 per cent in formal non-agricultural employment (Department of Finance, 1996). However, in terms of employment creation, GEAR performed poorly: formal employment continued to fall, or at best stagnated during the latter half of the 1990s. ${ }^{17}$ Bhorat et al. (2005) conclude that GEAR achieved its goals in terms of fiscal and macroeconomic stability, thus creating a platform for growth. However, the welfare challenges remained.

The post-GEAR period has seen "a shift in the policy stance towards government having a more direct role in promoting economic expansion" (Bhorat et al., 2005:4), particularly through the implementation of microeconomic strategies aimed at improving skills, increasing efficiency, removing constraints to business development, and so on. In contrast to GEAR, it was now felt that increased expenditure in social and economic infrastructure would crowd in rather than crowd out investment. Policymakers felt that greater attention to detail would ensure that resulting economic growth had a more meaningful impact on employment creation and poverty reduction. To some extent, it appears as if government is reverting back to a macroeconomic strategy that is more in line with the RDP than with GEAR - a notion strengthened by the government's more recent Accelerated and Shared Growth Initiative for South Africa (ASGISA). Many of the ASGISA proposals emphasise the importance of publiclyfunded infrastructural investments as a key to improving the productive capacity and future growth potential of the economy. 


\subsection{ECONOMIC PERFORMANCE: HAS GROWTH BEEN PRO-POOR?}

\subsubsection{Policy and Growth Targets}

The economic growth and employment targets of GEAR were given a lot of media coverage and to some extent became the benchmark against which the government's success in terms of macroeconomic policies were measured during the first decade after apartheid. But the government also deserves to be commended for a number of other successes. Various fiscal policy objectives, including the implementation of a sound and comprehensive budgeting process, the excellent performance of the South African Revenue Services (SARS) in terms of revenue collection and widening of the tax base, as well as the reduction achieved in the fiscal deficit and in the debt-to-GDP ratio, were all accomplished during the GEAR period.

Figure 14 shows that real GDP growth was positive, albeit low, during the first decade after apartheid. It was hoped that private sector investment, complemented by public investment, would be the main driver of growth. Although gross fixed capital formation grew at an average 5.1 per cent between 1994 and 2003, this was "clearly inadequate to generate the economic growth necessary for the large-scale job creation and poverty alleviation required" (Bhorat et al., 2005:7). The lower-than-required investment levels were a result of a tight monetary policy at the time, driven largely by a strong policy focus on protecting the value of the South African currency (Rand) during a period of regular domestic and international crises. A general lack of investor confidence also prevailed at the time. ${ }^{18}$ Public sector investment was also constrained, in line with the policy goal of rapidly reducing the government deficit.

FIGURE 14

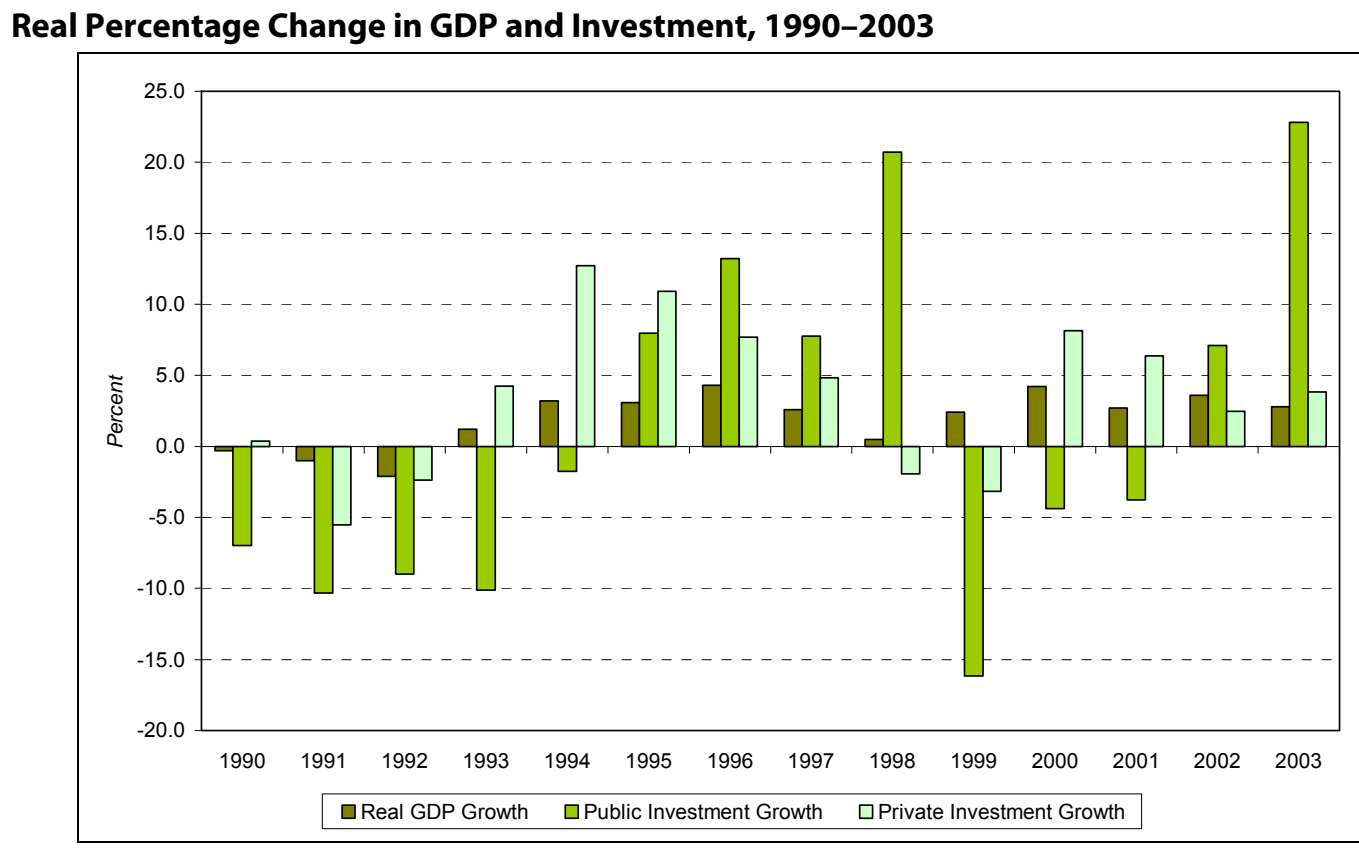

Source: Bhorat et al. (2005), based on National Accounts, SARB 2005.

Consumer spending was strong during the period, outpacing growth in GDP and in disposable household income. However, Bhorat et al. (2005) point out that most of this spending was directed at imports, despite the weak Rand, thus doing little to boost domestic 
production. In summary then, growth was well below expected levels and well below the levels required to make inroads into poverty through job creation. A number of questions need to be asked. Is growth really the answer to the need for job creation? Or perhaps put differently, can the type of growth experienced explain why job creation was not an inevitable outcome? Sections 3.2.2 and 3.2.3 look at job creation rates (output-employment elasticities) and at whether the growth that was experienced actually benefited the poor in South Africa.

\subsubsection{Is Growth the Answer to Job Creation and Poverty Reduction?}

Output-employment elasticities are useful for evaluating the impact of growth on employment creation. The output-employment elasticity is defined as the rate of job creation for a given percentage growth in the economy. The output-employment elasticity for South Africa as a whole has been below one ever since the 1970s, and even dipped below zero during the 1990s - a period characterised by jobless growth (Bhorat et al., 2005). Whether the output-employment elasticity will rise above one in the next decade remains anyone's guess, but given the historical trends, this is unlikely.

The current unemployment rate (broad definition) is about 38.8 per cent (LFS 2005). During the last decade the South African labour force has been growing at an average of 3.9 per cent per annum (DPRU, 2006). Assuming that the labour force growth rate remains stable and that the employment-output coefficient recovers to around 0.8 , then simple arithmetic reveals that the growth rate required to halve unemployment by 2015 (to 19.4 per cent) is around 8.5 per cent per annum (ceteris paribus). Various scenarios can be explored based on the assumption that the unemployment rate in some future period $\left(u_{T}\right)$ is a function of the time elapsed $(t)$, the expected growth in labour supply $(I)$ - assumed to be constant here -, the GDP growth rate $(y)$ and the output-employment elasticity $(\eta)$.

$$
u_{T}=f(y, \eta, l, t)
$$

Table 7 shows the predicted unemployment rates for $2015(t=10)$, for various combinations of employment-output elasticities and GDP growth rates, given a labour supply growth of $I=3.9$ per cent. The grey block of shaded cells represents the range of unemployment rates that would result if the economy grew at between 4 and 6 per cent and if the employment-output elasticity ranged between 0.6 and 1.0. These are deemed fairly optimistic ranges for both the growth rate and the employment-output elasticity. The dark shaded cells running diagonally across the matrix represent unemployment rates below the 19.4 per cent target. Clearly, the corresponding growth and/or employment elasticities associated with these unemployment rates are highly optimistic, judging by South Africa's past economic performance. The empty cells represent combinations of growth and employment elasticities that would result (mathematically speaking) in negative unemployment estimates, which is why they are deleted. The message, however, is clear: a reliance on growth alone to halve unemployment is overly ambitious. Furthermore, historic trends in output-employment elasticities for South Africa suggest that the economy will never be able to generate enough jobs through growth alone in order to halve unemployment. 
TABLE 7

Predicted Unemployment Rates in 2015

\begin{tabular}{|c|c|c|c|c|c|c|c|c|c|c|c|}
\hline & & \multicolumn{10}{|c|}{ Possible Output-Employment Elasticities } \\
\hline & & 0.2 & 0.4 & 0.6 & 0.8 & 1.0 & 1.2 & 1.4 & 1.6 & 1.8 & 2.0 \\
\hline \multirow{10}{*}{ 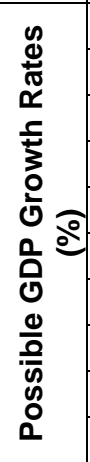 } & $1 \%$ & $57 \%$ & $56 \%$ & $56 \%$ & $55 \%$ & $54 \%$ & $53 \%$ & $52 \%$ & $51 \%$ & $50 \%$ & $49 \%$ \\
\hline & $2 \%$ & $56 \%$ & $55 \%$ & $53 \%$ & $51 \%$ & $49 \%$ & $47 \%$ & $45 \%$ & $43 \%$ & $40 \%$ & $38 \%$ \\
\hline & $3 \%$ & $56 \%$ & $53 \%$ & $50 \%$ & $47 \%$ & $44 \%$ & $40 \%$ & $37 \%$ & $33 \%$ & $29 \%$ & $25 \%$ \\
\hline & $4 \%$ & $55 \%$ & $51 \%$ & $47 \%$ & $43 \%$ & $38 \%$ & $33 \%$ & $28 \%$ & $22 \%$ & $16 \%$ & $10 \%$ \\
\hline & $5 \%$ & $54 \%$ & $49 \%$ & $44 \%$ & $38 \%$ & $32 \%$ & $25 \%$ & $18 \%$ & $10 \%$ & $1 \%$ & - \\
\hline & $6 \%$ & $53 \%$ & $47 \%$ & $40 \%$ & $33 \%$ & $25 \%$ & $16 \%$ & $6 \%$ & - & - & - \\
\hline & $7 \%$ & $52 \%$ & $45 \%$ & $37 \%$ & $28 \%$ & $18 \%$ & $6 \%$ & - & - & - & - \\
\hline & $8 \%$ & $51 \%$ & $43 \%$ & $33 \%$ & $22 \%$ & $10 \%$ & - & - & - & - & - \\
\hline & $9 \%$ & $50 \%$ & $40 \%$ & $29 \%$ & $16 \%$ & $1 \%$ & - & - & - & - & - \\
\hline & $10 \%$ & $49 \%$ & $38 \%$ & $25 \%$ & $10 \%$ & - & - & - & - & - & - \\
\hline
\end{tabular}

\subsubsection{Has Growth Been Pro-Poor?}

There are a number of approaches to determining whether growth is pro-poor (see Bhorat et al., 2005). One such approach is to examine a growth incidence curve (GIC), which plots the growth in expenditure across each percentile of the distribution. Bhorat et al. (2005) show that the mean of the expenditure growth rates at each percentile was approximately three per cent between 1995 and 2000. The GIC only exceeds this mean at about the 70 $70^{\text {th }}$ percentile of individuals, meaning that less than one-third of the individuals experienced welfare gains above the national average. The GIC is furthermore sloping upward over the entire distribution, with those at the bottom end experiencing the lowest growth rates. This suggests that growth was not pro-poor between 1995 and 2000. Bhorat et al. further find a clear racial bias in the expenditure growth rates, with Coloured and White expenditures growing at a much faster rate than African expenditures: "it is evident that the Coloured and White poor realised significantly greater gains than their African counterparts in this period, which is suggestive of a racial bias within this already tepid pro-poor growth performance" (2005:36).

A more nuanced approach to measuring pro-poor growth evaluates the impact of both growth and changes in inequality on poverty rates. This approach is based on the decomposition described in equation [2]. Understanding the impact of growth on poverty requires an understanding, firstly, of how changes in mean income impact on poverty and, secondly, of how changes in inequality impact on poverty. Following Kakwani (1993), let $\theta$ be the poverty index for poverty line $z$ and mean per capita income $\mu$. If inequality is represented by a Lorenz curve characterised by $k$ parameters, $m_{1}, \ldots, m_{k}$, we can then write for a fixed poverty line:

$$
d \theta=\frac{\partial \theta}{\partial \mu} d \mu+\sum_{i=1}^{k} \frac{\partial \theta}{\partial m_{i}} d m_{i}
$$

This equation decomposes the change in poverty $(d \theta)$ into components relating to the impact of growth for a constant income distribution (left-hand term) and to the impact of income redistribution for a constant income level (right-hand term). These two effects are respectively referred to as the 'pure growth effect' and the 'inequality effect' (Kakwani, 1993). For positive economic growth, the pure growth effect will always be zero or negative. As long as 
the inequality effect is less than the absolute value of the pure growth effect, the net effect of growth on poverty will be negative - the so-called trickle-down effect of growth.

In applying this methodology to the FGT poverty measures - specifically $P_{1}$ and $P_{2}-$, the poverty-growth elasticity can be calculated using the following equation:

$$
\eta_{P_{\alpha}}=-\frac{\alpha\left[P_{\alpha-1}-P_{\alpha}\right]}{P_{\alpha}} \text { for } \alpha \neq 0
$$

This effect measures the pure growth effect on poverty reduction with inequality held constant. For the FGT poverty measures, it can now be shown that the elasticity of the $P_{\alpha}$ poverty measure for a given change in the Gini coefficient is provided by the expression (Kakwani, 1993):

$$
\varepsilon_{P_{\alpha}}=\eta_{P_{\alpha}}+\frac{\alpha \mu P_{\alpha-1}}{z P_{\alpha}} \text { for } \alpha \neq 0
$$

The marginal proportional rate of substitution (MPRS) between mean income and income inequality can then be calculated. This illustrates the trade-off between the effects of mean income growth and changes in inequality on overall poverty and allows the analyst to determine the required percentage increase in mean income that would counter the negative impact of increasing inequality on poverty.

$$
M P R S=-\frac{\varepsilon_{P_{\alpha}}}{\eta_{P_{\alpha}}}
$$

Bhorat et al. (2005) apply the above methods to the IES datasets for 1995 and 2000, using the Hoogeveen and Özler (2004) poverty lines of R322 and R174 per capita per month. Their results for the $P_{1}$ poverty estimate are shown in Table 8 . Two interesting observations can be made with regard to the mean income elasticity (mean income is used here as a proxy for economic growth). Firstly, the elasticity estimates declined between 1995 and 2000 at both poverty lines, suggesting that growth has had less effect on poverty over time. Secondly, however, the elasticity estimates are much higher at the lower poverty line, suggesting that income growth has "a magnified impact on the ultra-poor" (Bhorat et al., 2005).

TABLE 8

Elasticities of Poverty Measures for South Africa, 1995-2000

\begin{tabular}{|l|c|c|c|c|}
\hline Category & \multicolumn{2}{|c|}{ Poverty line R322 p.c. } & \multicolumn{2}{|c|}{ Poverty line R174 p.c. } \\
\hline Year & $\mathbf{1 9 9 5}$ & $\mathbf{2 0 0 0}$ & $\mathbf{1 9 9 5}$ & $\mathbf{2 0 0 0}$ \\
\hline Mean Income Elasticity for $P_{1}$ & -1.00 & -0.87 & -1.58 & -1.38 \\
\hline Gini Elasticity for $P_{1}$ & 2.45 & 3.48 & 6.66 & 8.84 \\
\hline MPRS for $P_{1}$ & 2.45 & 3.99 & 4.21 & 6.43 \\
\hline
\end{tabular}

Source: Selected results from Bhorat et al. (2005), based on calculations using the IES 1995 and 2000.

The inequality elasticity estimates for the standard poverty line show that for a one per cent increase in the Gini coefficient, the poverty gap $\left(P_{1}\right)$ would increase by 2.45 and 3.48 
per cent in 1995 and 2000 respectively. These elasticities rise significantly at the lower poverty line. Clearly, as Bhorat et al. (2005) conclude, increases in inequality can cause significant increases in poverty. Finally, the MPRS measures at the standard poverty line show that a growth in mean income of 2.45 and 3.99 per cent is needed to counter the impact of a one per cent rise in inequality in 1995 and 2000 respectively. Not only did the MPRS increase between 1995 and 2000, but it also became much higher at the lower poverty line. This suggests that even higher growth in mean incomes is required to counter the impact of an increase in inequality on ultra-poverty.

\subsection{THE POST-APARTHEID LABOUR MARKET EXPERIENCE ${ }^{19}$}

Some important structural shifts have taken place in the South African economy and labour market during the last decade. Most apparent has been the shift in output away from primary and secondary sectors towards services or tertiary sectors (Bhorat and Oosthuizen, 2005), an expected trend to any developing economy. This has brought about a change in the demand patterns for different types of labour, due to differences in the levels of skills required by each sector. Most notably, there has been an increase in demand for skilled labour at the expense of unskilled workers (Burger and Woolard, 2005). This section briefly examines the reasons for and the nature of these structural shifts, as well as the implications for the labour market and the poor.

A variety of factors have contributed to the structural change observed in the South African economy. Domestic firms have in the past decade or so been forced to adopt improved production techniques in order to remain competitive in the face of globalisation, trade liberalisation and, more recently, the strengthening of the currency. Production efficiency gains enable producers to turn out a unit of output using fewer inputs than before, thus often leading - depending on the demand-side effect of the resulting lower commodity prices - to a decrease in demand for factors of production.

Such gains have been especially prevalent in the primary sectors of agriculture and mining, both of which employ a large proportion of low-skilled (or low-wage) workers. This has resulted in a decline in employment in these industries (Burger and Woolard, 2005). The technical change experienced by such sectors has been mostly capital-deepening, that is, capital-labour ratios have increased as production processes have become more capital intensive. Bhorat and Oosthuizen suggest that, in general, such technical change is "viewed in a relatively negative light due to [its] dampening on the employment-increasing effect of output expansion" (2005:12). Intuitively speaking, however, one would expect greater capital intensity to actually increase the demand for high-skilled workers, albeit at the expense of low-skilled workers. This is due to the fact that firms demand more skilled workers who are "required to operate and maintain the new capital equipment" (Bhorat and Hodge, 1999:352). ${ }^{20}$

Other studies in the past have focused more on the effects of trade liberalisation on the structure of employment. Bell and Cattaneo (1997) find that "trade flows have shifted production away from Black intensive sectors towards White intensive (or skill intensive) sectors" (as cited in Edwards, 2001a). A more recent study by Dunne and Edwards (2005) finds that tariffs fell relatively sharply in labour intensive sectors, particularly those with large shares of low-skilled workers, and as a result the direct employment effect of liberalisation has been biased against low-skilled workers. Their analysis further shows that, in addition to the negative impact in labour-intensive sectors, metal products sectors also experienced a decline 
in labour demand, while the capital-intensive resource-based and chemical products sectors experienced positive employment effects.

Factor costs have also undoubtedly had an important impact on the structure and levels of employment in South Africa. The capital intensification of the economy was partly due to a reduction in the cost of capital relative to other factors of production through subsidisation of capital-intensive industries (tax breaks and preferential interest rates). According to Edwards (2001b), financial support for certain capital-intensive industries such as chemicals and iron \& steel continued during the 1990s. Real wage increases and changes in relative wages have put further pressure on employment levels, particularly for low-skilled workers. Although comparisons over long periods in South Africa's history are problematic to draw, Lewis (2001) estimates that the real wage of semi- and unskilled workers increased by 150 per cent between 1970 and 1999. In stark contrast, wages of highly skilled workers declined while those of skilled workers rose by approximately 10 per cent over that period. At the same time, Nattrass (2000) argues that the post-1994 period has seen increases in non-wage costs of employment due to stricter labour market legislation. Evidence such as this leads Burger and Woolard (2005) to conclude that wage levels for some low-skilled workers are above their market clearing levels, which make them relatively less attractive than skilled workers.

It is impossible to disentangle the relative importance of economic development, technical progress, trade liberalisation, and increases in real wage and non-wage costs of labour in altering labour demand patterns in South Africa. However, all these effects have contributed to the economy's skills-biased labour demand trajectory. The welfare implications of these structural changes are interesting. In an analysis of (trade-induced) skill-biased structural change in the South African economy, Pauw et al. (2006:52) find that poor households often "lack connections to the labour market and especially to the better remunerated section s the labour market". This is both due to the fact that individuals in poor households often live farther from formal sector job opportunities (e.g. rural areas) and that they do not posses the skills to compete for jobs. This disconnection from the formal economy implies that poor households are often more reliant on non-labour income sources such as government transfers and less vulnerable to changes in employment demand patterns caused by structural changes in the economy.

Although - as argued in the preceding paragraphs - alterations in labour demand patterns induced by structural changes are unlikely to have significant welfare implications for the very poorest in society, it is still instructive to consider the education profiles (as a proxy for skill levels) of individuals in the labour force who are either poor or non-poor. For the sake of simplicity, we assume that individuals in the bottom two household quintiles as defined in section 2.1 are poor and the rest are non-poor. Figure 15 shows the distribution of poor and non-poor labour market participants, including employed and unemployed individuals, across different education cohorts, namely low education (primary school or below), middle education (lower secondary, i.e. up to Grade 10) and high education (upper secondary, inclusive of Grade 12 and tertiary qualifications).

Among those employed, people with high education levels are more likely to be nonpoor if we associate the large number of observations in this cohort with a larger likelihood or probability. The same is true for unemployed persons - a higher education level is associated with a larger probability of being non-poor. This probably reflects the fact that non-poor unemployed persons with high education levels are more likely to be temporarily unemployed and/or have alternative income sources, be it from asset ownership or from other members of the family. Among the employed, people with low education levels are more likely to be poor 
(the working poor). The same also seems to hold for the unemployed. It is further quite likely that unemployed people with low education levels fall into the group of structurally unemployed persons.

Figure 15 represents a very simplistic way of analysing the issue. Although further analysis is required to substantiate its results, it does perhaps tell a story of how the poor are more likely to be adversely affected by structural changes. As argued before, the structural changes that have taken place (and are likely to continue to do so in the future) have benefited highly skilled workers at the expense of low-skilled workers. This implies that more jobs in the highly-skilled categories have become available, while fewer opportunities now exist in the low-skilled categories. If we associate skills with education levels, then it is quite likely that as more high-skill (high-education) jobs become available, the individuals that compete for these jobs - whether unemployed or currently employed - will be non-poor. But as low-skill (low-education) jobs are shed, the working poor are more likely to be adversely affected. ${ }^{21}$

FIGURE 15

\section{Education Levels of Poor and Non-Poor Labour Market Participants}

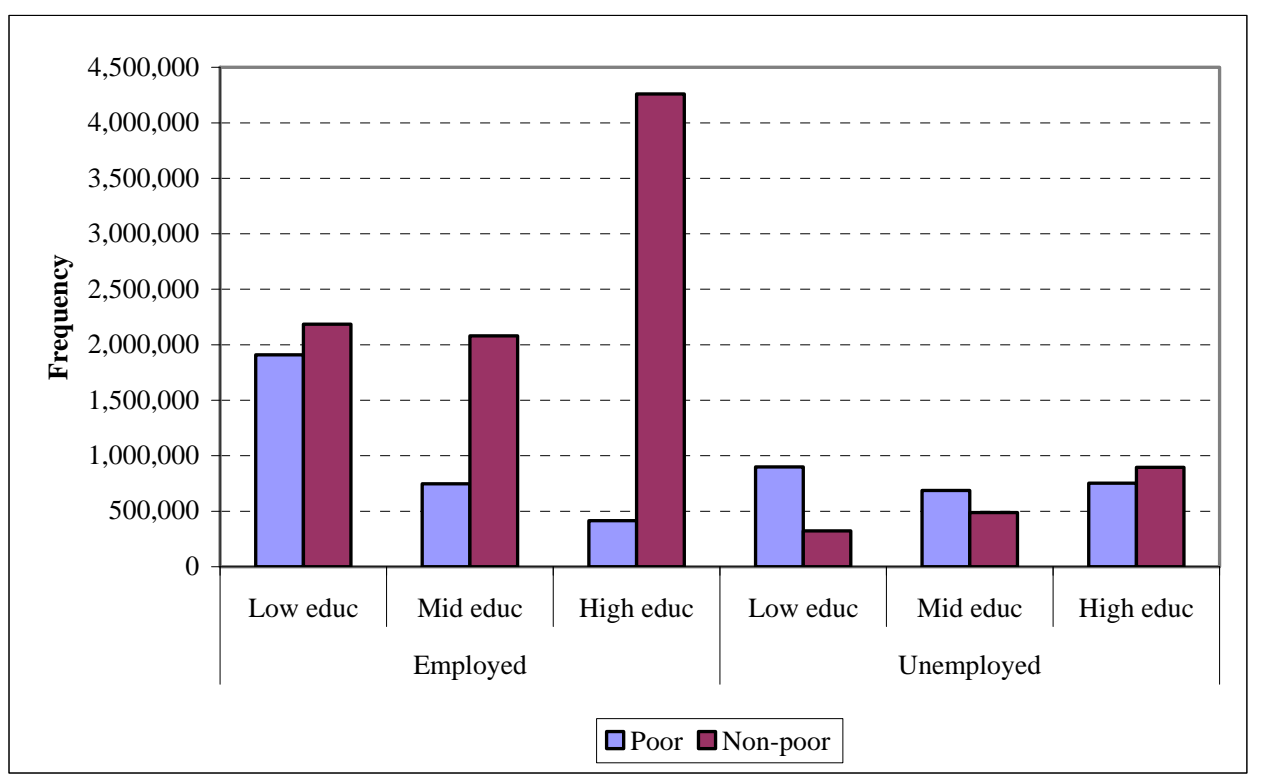

Source: IES 2000.

Note: For simplicity we assume that individuals in the bottom two household per capita income quintiles (see section 2.1) are poor.

\section{POVERTY AND SOCIAL SECURITY PROVISIONING IN SOUTH AFRICA}

There appears to be some degree of consensus that incomes declined and poverty increased between 1995 and 2000. The economy's poor track record in terms of job creation played a big role in this regard. In this section we look at social security provisioning in South Africa and how this has impacted on poverty. First, however, we review the role of taxes and welfare transfers in redistributing income in South Africa. Following that, we consider the degree to which welfare transfers have been successfully targeted at the poor. Finally, we briefly consider the large increases in welfare transfer spending in South Africa over the last decade. 


\subsection{TRANSFERS AND TAXES AS TOOLS FOR REDISTRIBUTION, 1995 - 2000}

Table 9 shows the mean estimates and Gini coefficients of some alternative welfare measures. These alternative measures include: (1) gross per capita income before welfare transfers; (2) gross per capita income after transfers; and (3) net disposable income, i.e., after taxes have been deducted. The first income measure gives an indication of the income levels that would have prevailed in the absence of a government that imposes taxes and makes welfare payments. The second and third income measures give an indication of the effectiveness of the government's policies of direct income redistribution through welfare transfers and taxes, respectively, in reducing inequality.

The net effect of transfers and taxes clearly benefits poor people..$^{22}$ In 1995, their disposable income was 35.7 per cent higher than their gross income before transfers, while in 2000 the difference was slightly less, at 30.2 per cent. For non-poor people, the net effect of taxes and transfers was negative in both years (12.1 and 9.0 per cent, respectively). The worrying aspect of per capita incomes, however, is that the incomes of poor people have declined, while that of non-poor people have risen. This explains why inequality has been on the rise, as the rich are apparently getting richer while the poor are getting poorer. ${ }^{23}$ Another concern is that the average transfer per poor person seems to be declining in real terms (i.e., the difference between (1) and (2) in Table 9). In 1995, the average welfare transfer value per poor person was R624 (2000 prices), in contrast to R465 in 2000. The equivalent values for non-poor persons remained fairly stable at R559 and R564, for 1995 and 2000, respectively.

TABLE 9

Average Incomes and Inequality, 1995 - 2000

\begin{tabular}{|c|c|c|c|c|c|c|c|c|c|c|c|c|}
\hline & \multicolumn{3}{|c|}{1995 (2000 prices) } & \multicolumn{3}{|c|}{2000} & \multicolumn{3}{|c|}{$\begin{array}{l}\text { Changes in real } \\
\text { income }\end{array}$} & \multicolumn{3}{|c|}{ Gini coefficient } \\
\hline & Poor & $\begin{array}{l}\text { Non- } \\
\text { poor }\end{array}$ & All & Poor & $\begin{array}{l}\text { Non- } \\
\text { poor }\end{array}$ & All & Poor & $\begin{array}{l}\text { Non- } \\
\text { poor }\end{array}$ & All & 1995 & 2000 & Change \\
\hline $\begin{array}{l}\text { Gross per capita income before } \\
\text { transfers (1) }\end{array}$ & 1,553 & 20,853 & 12,807 & 1,456 & 22,110 & 11,704 & $-6.2 \%$ & $6.0 \%$ & $-8.6 \%$ & 0.675 & 0.721 & $6.9 \%$ \\
\hline $\begin{array}{l}\text { Gross per capita income after } \\
\text { transfers (2) }\end{array}$ & 2,177 & 21,412 & 13,393 & 1,921 & 22,674 & 12,218 & $-11.8 \%$ & $5.9 \%$ & $-8.8 \%$ & 0.653 & 0.698 & $6.9 \%$ \\
\hline $\begin{array}{l}\text { Net per capita income } \\
\text { (disposable income) (3) }\end{array}$ & 2,108 & 18,326 & 11,565 & 1,896 & 20,128 & 10,942 & $-10.1 \%$ & $9.8 \%$ & $-5.4 \%$ & 0.636 & 0.678 & $6.6 \%$ \\
\hline Percentage change (from 1 to 3 ) & $35.7 \%$ & $-12.1 \%$ & $-9.7 \%$ & $30.2 \%$ & $-9.0 \%$ & $-6.5 \%$ & & & & $-5.7 \%$ & $-5.9 \%$ & \\
\hline
\end{tabular}

Source: IES 1995 and 2000, authors' own calculations.

The Gini coefficient for all these income measures increased between 1995 and 2000. However, the table also shows that inequality is reduced by direct redistribution policies. In particular, transfers, which are targeted at low-income recipients, and taxes, which are targeted at middle- to high-income people, reduced inequality from 0.675 to 0.636 (a 5.7 per cent reduction) in 1995, and from 0.721 to 0.678 (a 5.9 per cent reduction) in 2000. Thus, although inequality is on the rise, it appears that redistributive policies are now doing about the same in reducing inequality as in the past. 


\subsection{IS THE GOVERNMENT'S SOCIAL WELFARE GRANT SPENDING PRO-POOR?}

Van der Berg's (2005) study of the welfare incidence of public spending, including welfare grants, finds that, of all public spending (including education, health and housing), expenditure on social grants was by far the best targeted to poor people in 1995 . This is to be expected, given the use of means testing to determine a grant recipient's eligibility. Also contributing to this result is the fact that the unemployed and children tend to cluster around old-age pension (OAP) recipients. This reduces the per capita incomes in such households which in turn increases the likelihood of the household being defined as poor. The targeting of social welfare spending appears to be somewhat less efficient in 2000 than in 1995. Van der Berg (2005) believes that the introduction of child support grants (CSG) during this period led to, at least initially, some loss in targeting precision. CSG means testing is difficult to implement since it has to be "very finely grained to separate the lowest 40 per cent of the child population", while urban households had earlier access to the benefit than rural households, thus initially excluding many of the poorest from coverage (Van der Berg, 2005:19).

However, Van der Berg (2005) admits that this result may be due to the way in which households are ranked for this particular incidence analysis. The parameters used to measure welfare exclude grant income. In pensioner households the pension is often the only source of income, thus reducing the welfare measurement to zero. This implies that a disproportionate number of OAP recipients will be located at the very bottom of the income distribution. In CSG-recipient households there are often other sources of income, so that the CSG appears to be benefiting more households with some non-grant income as opposed to those with none. Figure 16 (from Bhorat et al., 2005) shows the concentration curve, defined as the cumulative proportion of spending going to cumulative proportions of the population, where the population is ranked by a welfare measure (in this case, per capita expenditure). The fact that the CSG concentration curve crosses above that of the OAP supports the argument that the CSG supports more households with some non-grant income.

From Figure 16 (page 34), it becomes clear that poorer households receive a disproportionately large share of grants. Bhorat et al. (2005:25) note that "more than two-thirds of grant recipients live in the poorest 50 per cent of households", as ranked by per capita expenditure. Consequently, it is not surprising that grants have an important poverty-reducing impact. Woolard (2003) finds that, in the absence of the OAP, 56 per cent of the elderly would be poor and 38 per cent would be ultra-poor. ${ }^{24}$ Assuming perfect uptake of the grant, these poverty rates decline to 23 per cent (poor) and 2.5 per cent (ultra-poor). The CSG is also highly effective in reducing poverty. Poverty among children under the age of seven ${ }^{25}$ would decline from 43 to 34 per cent in the case of complete uptake of the grant, while ultra-poverty would decline from 13 to four per cent. The combined impact of OAPs and CSGs, assuming perfect uptake, would lower poverty from 40 to 24 per cent, while reducing the Gini coefficient of household per capita expenditure from 0.67 to 0.62 (Woolard, 2003). 
FIGURE 16

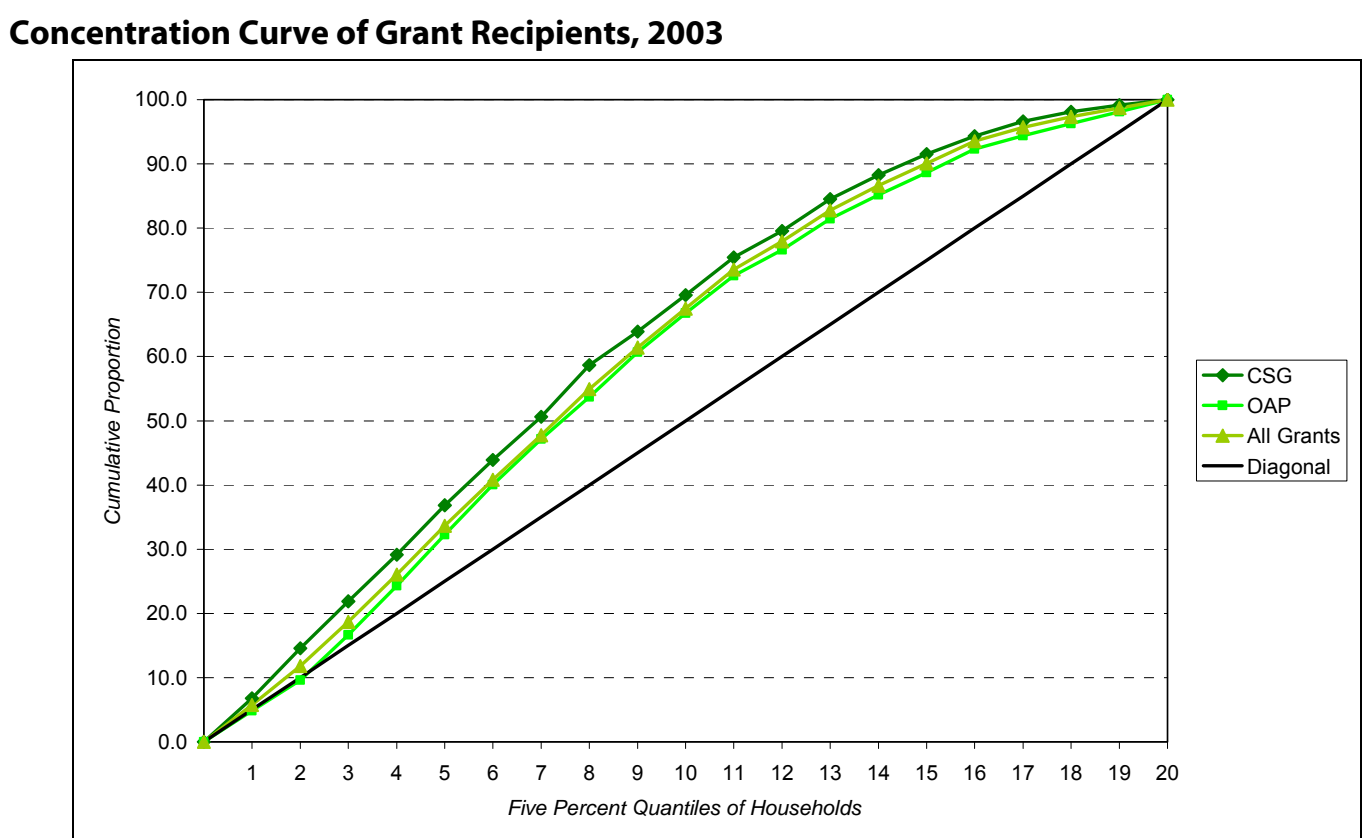

Source: Bhorat et al. (2005), based on the GHS 2003.

Note: Bhorat et al. (2005:26) note that "since quantiles were constructed from household expenditure, the concentration curve will be slightly warped at the lower end." Furthermore, "on pre-transfer income, grant-receiving households would tend to be located right near the bottom of the income distribution". The concentration curve derived by Van der Berg (2005:19) - which is based on pre-transfer income - shows a prominent 'bulge' at the lower end of the distribution.

\subsection{INCREASES IN WELFARE SPENDING BY GOVERNMENT, 1995 - 2005}

Van der Berg et al. (2005) ascribe the turnaround in the trend of declining incomes and increasing poverty since 2000 to improved job creation and a significant increase in public spending on welfare grants. With regards to the latter, they argue that welfare grants typically benefit the poor in society, since their targeting is based on means testing. According to their estimates, the total income accruing to the bottom two quintiles in 2000 was about R27 billion. They further estimate that the real increase in welfare spending verified between 2000 and 2004 alone was R22 billion in real terms (constant 2000 prices). Based on this evidence, their results showing very large increases in income among the poorare plausible.

The preceding discussions have shown how national economic policies between 1996 and 2001 were based on fiscal prudence, in an effort to reduce government debt and keep inflation in check. The government - it was argued - was very successful in this regard. Since 2001, however, government expenditure started increasing, with Trevor Manuel making the government's intent quite clear in his Budget Speech (2001):

"We can now embrace a more confident and expansionary vision. This Budget tells the story of the choices and decisions we have made and which have advanced the transformation of our country and its economy to the point where we can now begin to enjoy its fruits."

Welfare grants are funded from the welfare budget, which in turn forms part of the social services budget in South Africa. Welfare grants are currently administered through a centralised institution called the South African Social Security Agency (SASSA). Previously 
grants were administered through the provincial departments of Social Development (previously Welfare). Given these administrative changes, it is fairly difficult to analyse welfare grant expenditure trends. This has led us to concentrate our focus on the total consolidated welfare budget of national and provincial governments from 1995 to 2005. It is also difficult to find reliable estimates of actual welfare payments for all the years covered, especially prior to 2000. According to the Budget Review of 2000 (published on the National Treasury's website at www.treasury.gov.za), up to 90 per cent of the total welfare budget comprise grant payments, and although this share did not remain absolutely stable over time, the trend in the total welfare budget is arguably a good indication of the trend in welfare payments as well.

In order to analyse trends in expenditure on welfare, government budgets dating back to 1995 were analysed. The South African budgeting system is based on a three-year rolling budget system called the Medium Term Expenditure Framework (MTEF). This means that for each fiscal year, the budget for the upcoming three years is specified. Budget Reviews for 1998 (the oldest available) to 2005 were used for the analysis. Budget Review 1998 includes welfare budgets for the 1995/96 to 1997/98 period, as well as MTEF estimates for 1998/99 to 2000/01. Budget Review 1999 contains MTEF estimates for 1999/00 to 2001/02, Budget Review 2000 contains MTEF estimates for 2000/01 to 2002/03, and so forth. Thus, three separate MTEF estimates are available for each budget year from the 1999/00 fiscal year onwards.

Figure 17 (page 36) shows the welfare budgets from 1995 to 2005. These figures are expressed in real terms (2000 prices), with actual (nominal) budgeted figures adjusted using the CPI deflator from Statistics South Africa. Up until the budget for 2000, which included MTEF estimates for 2000/01 to 2002/03, the welfare budget remained fairly stable in real terms, at around R20 000 million. However, revisions for 2001/02 and 2002/03 published in the Budget Review 2001 were suddenly significantly higher, reaching about R30 000 million in real prices. From then on, each revised MTEF made further upward adjustments, eventually taking the budget up to R56 819 million for the 2005/06 budget year, as estimated in Budget Review 2005. These figures make it clear that there was a definite structural break in the trend of welfare spending in South Africa from 2001 onwards.

Figure 18 (page 36) shows the percentage changes (in real terms) in welfare budget over this period. Although the year-on-year growth rate was fairly erratic, with the largest growth (43 per cent) appearing in the 2001/02 budget, the average real growth over the period $1996 / 97$ to $2005 / 06$ was just over 10 per cent. However, the figures also show the average growth rates for the period $1995 / 96$ to $2000 / 01$, and again for $2000 / 01$ to $2005 / 06$. In the period up to 2000, the real growth in welfare spending was around zero per cent, i.e., it just kept pace with inflation. From 2000 onwards, however, it grew at an average of about 22 per cent, which has been well above the inflation rate. MTEF estimates for 2006/07 and 2007/08, as provided in the Budget Review 2005, predict further real growth rates of 6.0 and 3.8 per cent, respectively, based on the assumption that the inflation rate will remain stable at around 4.5 per cent during this period.

Much of the growth in real welfare expenditure is attributed to a large increase in the uptake of welfare grants, especially those relating to child care. Although figures are fairly hard to come by, the Budget Review 1998 published estimates of the number of beneficiaries within each type of welfare grant. More recently, in the provincial budgets and expenditure review of 2006, the number of beneficiaries was again published, this time for the period 2000 to 2006. Table 10 (page 37) shows the growth in the number of beneficiaries over time, particularly for the years 1997 to 2006. The total number of beneficiaries grew by 15.4 per cent per annum. 
Most of this growth is attributed to very high growth rates in the number of care dependency and child support grant recipients.

FIGURE 17

\section{Welfare Budgets, 1995 - 2005 (2000 prices)}

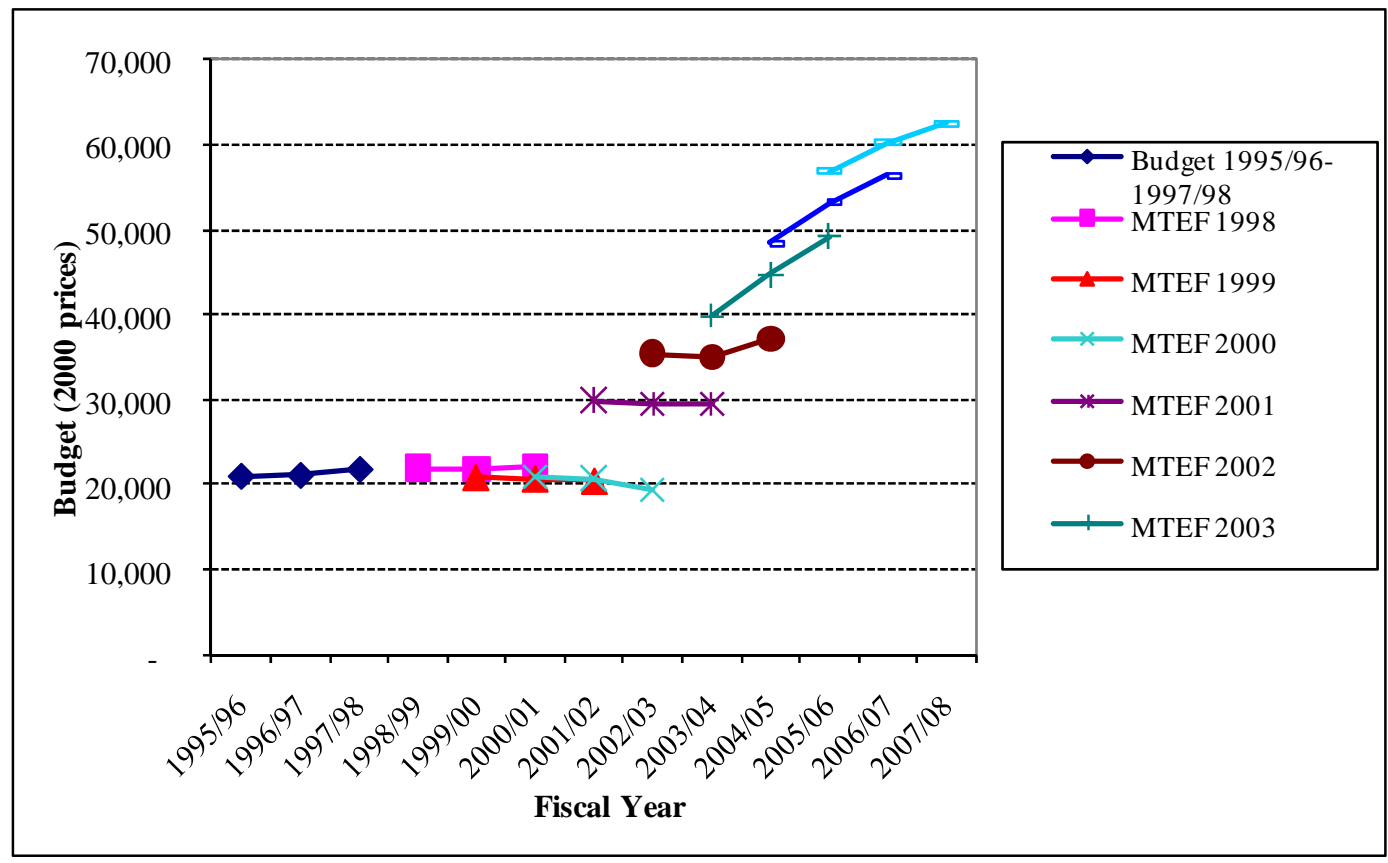

Source: National Treasury Budget Review (various years, available at www.treasury.gov.za).

FIGURE 18

\section{Percentage Changes in Welfare Budget}

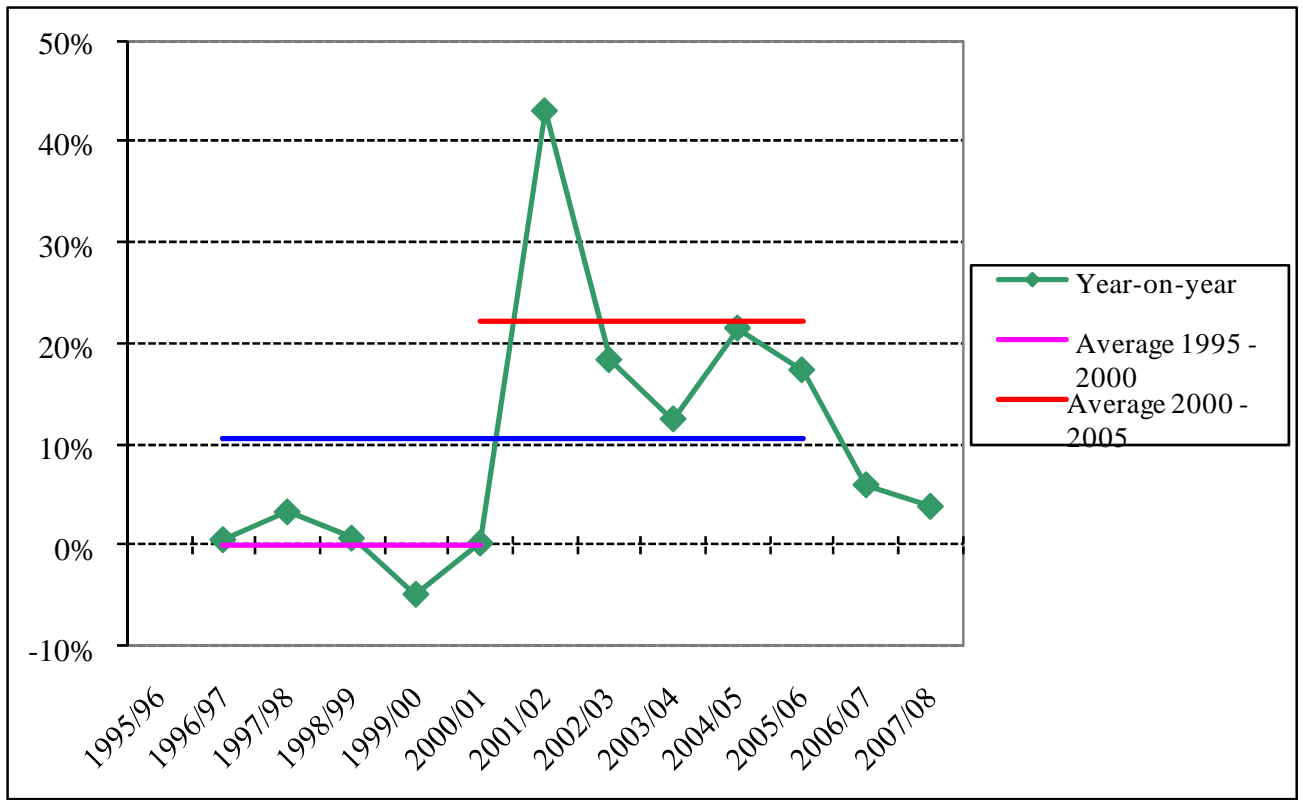

Source: National Treasury Budget Review (various years, available at www.treasury.gov.za). 
TABLE 10

Growth in the Number of Beneficiaries Per Grant Type, 1997 - 2006

\begin{tabular}{|l|r|r|r|r|r|r|r|r|}
\hline & \multicolumn{1}{|c|}{ Old age } & \multicolumn{1}{c|}{$\begin{array}{c}\text { War } \\
\text { veterans }\end{array}$} & Disability & \multicolumn{1}{c|}{$\begin{array}{c}\text { Grant } \\
\text { in aid }\end{array}$} & \multicolumn{1}{c|}{$\begin{array}{c}\text { Foster } \\
\text { care }\end{array}$} & \multicolumn{1}{c|}{$\begin{array}{c}\text { Care } \\
\text { dependency }\end{array}$} & \multicolumn{1}{c|}{$\begin{array}{c}\text { Child } \\
\text { support }\end{array}$} & \multicolumn{1}{c|}{ Total } \\
\hline $\begin{array}{l}\text { Beneficiaries } \\
\text { in 1997 }\end{array}$ & $1,742,253$ & 11,495 & 754,830 & 9,720 & 42,917 & 3,815 & 400,599 & $2,965,629$ \\
\hline $\begin{array}{l}\text { Beneficiaries } \\
\text { in 2006 }\end{array}$ & $2,126,373$ & 2,889 & $1,311,148$ & 26,217 & 299,865 & 88,679 & $6,894,428$ & $10,749,599$ \\
\hline $\begin{array}{l}\text { Average annual } \\
\% \text { growth }\end{array}$ & $2.2 \%$ & $-14.2 \%$ & $6.3 \%$ & $11.7 \%$ & $24.1 \%$ & $41.8 \%$ & $37.2 \%$ & $15.4 \%$ \\
\hline
\end{tabular}

Source: Department of Social Development (available at www.welfare.gov.za).

A comparison of figures for 'per capita benefit' - here defined simply as the total welfare budget divided by the total number of beneficiaries - indicates that it actually declined from R8 241 in 1995 to R5 601 in 2006. A change in the makeup of welfare grant recipients is the major reason. Old age pensioners currently receive a maximum $\mathrm{R} 820$ per annum, in contrast with the child support grant of only R190.

So, how have these sharp increases in welfare transfers been funded? Such increases were partly made possible by much improved tax collection rates achieved by the South African Revenue Services. However, there has also been a restructuring of the social services budget, which is certainly a concern. In addition to welfare spending, social services are mainly made up of expenditure on health, education and housing. The social services budget as a share of the total non-interest spending budget remained fairly stable, at around 60 per cent, during the last decade. However, welfare spending as a proportion of the overall social services budget has shown a fairly sharp increase, especially since the 2001/02 budget year. Whereas it averaged around 20 per cent prior to 2000 , it has now increased to almost 33 per cent in the latest budget estimates (see Figure 19). Given already poor service delivery in health, education and housing provision in South Africa, this restructuring of the budget is both puzzling and a source of concern.

FIGURE 19

Budget Shares, 1995/96 - 2007/08

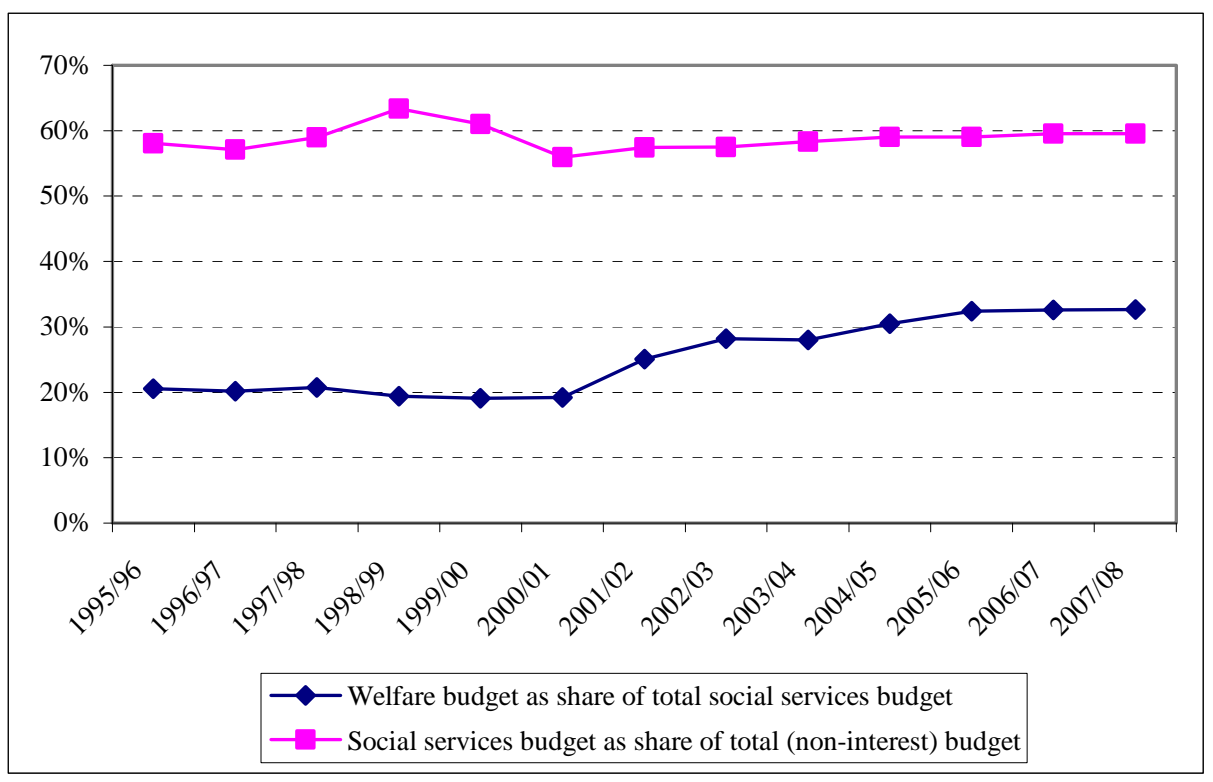




\section{CONCLUDING REMARKS}

More than a decade after the advent of democracy, the South African government still faces many of the same challenges encountered when the ANC took power in 1994. Poverty is still widespread, while the socio-economic problems associated with unemployment still persist. One of the main goals set by the new government was that of redressing inequalities and fighting poverty. Although the ultimate goal of economic and social policy is to allow more people to become self-sufficient through the creation of employment opportunities, it has since long been realised that a large proportion of the population will remain structurally unemployed or chronically poor. As a result, the central government has committed itself to providing safety nets, both as a temporary measure to assist the transitory poor and as a more permanent arrangement for the chronically poor.

The economy's limited growth and poor employment track record in the period between 1995 and 2001 took its toll on household incomes and poverty levels, much to the embarrassment of the government, given its initial ideals of high growth and employment creation as set out in the GEAR policy document. In hindsight, however, the policy of fiscal discipline and 'getting the fundamentals right' proved capable of creating an ideal platform from which to launch a renewed fight against poverty through increased government expenditure, especially on welfare transfers. In addition, the good performance of SARS in terms of tax collection and broadening of the tax base created the opportunities and impetus for increased welfare expenditure. However, as shown above, increased expenditure on welfare transfers was not entirely funded by these revenue overruns; in fact, the share of the total social services budget remained constant, while relatively more resources appear to have been channelled to welfare, and away from housing, education and health.

Today, a very large proportion of the population is reliant on welfare transfers, including old age pensions, disability grants, and - especially more recently - a variety of child maintenance and support grants. At least one quarter of all households in South Africa earns welfare transfer income, while about a third of these recipient households rely on these transfers for between 80 and 100 per cent of their income. The uptake of welfare transfers is on the rise due to a number of reasons: there is increased awareness of grants, welfare coverage has been extended dramatically since the 1990s, HIV/AIDS-related illnesses lead to higher dependency rates and lower household incomes, and the population is ageing. As households become smaller and more fragmented, the share of households relying on welfare transfers may become even larger.

Welfare transfer expenditure makes up approximately 30 per cent of the social services budget, which in turn accounts for about 60 per cent of the overall non-interest budget of the South African government. Thus, about 20 per cent of that overall budget is spent on welfare transfers - despite the fact that the tax base in South Africa is fairly narrow because of the high unemployment rate. Many have questioned the sustainability of having 10 million workers, of whom about three-quarters earn enough income to become eligible for income tax ${ }^{26}$ financing 10 million welfare transfer recipients. Admittedly, the average welfare grant - which ranges from R190 for child maintenance grants to R820 for the social old-age pension - is fairly low, so that the effective cost per taxpayer is relatively low. However, some analysts have raised concerns about calls for increased welfare transfer payments as a policy option to fight poverty. 
There is little doubt that the significant growth spurt in welfare transfer expenditure, especially between 2001 and 2004, has made important inroads into poverty and inequality. However, there seems to be a great deal of consensus that further increases well above the inflation rate are not sustainable. Another important issue is whether it is sensible to divert funds away from other crucial areas such as health and education in a society plagued by a high mortality rate associated with the HIV/AIDS pandemic and by exceptionally poor schooling outcomes. These are the important policy issues with which the government will have to grapple as it determines the future path of social security provisioning in South Africa. 


\section{REFERENCES}

Bell, T. and Cattaneo, N. (1997). "Foreign trade and employment in the South African manufacturing industry", Occasional Report, No. 4. Employment and Training Department, International Labour Organisation, Geneva.

Bhorat, H. and Hodge, J. (1999). "Decomposing Shifts in Labour Demand in South Africa", South African Journal of Economics, 67(3): 348-380.

Bhorat, H. and Oosthuizen, M. (2005). "What Have We Learnt about the South African Labour Market?" Development Policy Research Unit, University of Cape Town.

Bhorat, H., Oosthuizen, M. and Poswell, L. (2005). "The Post-Apartheid South African Economy in Perspective: Growth, Poverty and Economic Policy", RBA Regional Project for Economic Policies in Support of MDGs and Poverty Reduction. Development Policy Research Unit, University of Cape Town. March 2005.

Bhorat, H., Poswell, L. and Naidoo, P. (2004). "Dimensions of Poverty in Pos-Apartheid South Africa, 1996 - 2001: A Poverty Status Report". Development Policy Research Union, Cape Town. July 2004.

Burger, R. and Woolard, I. (2005). "The State of the Labour Market in South Africa after the First Decade of Democracy", CSSR Working Paper No. 133. Centre for Social Science Research, University of Cape Town.

Department of Finance (1996). "Growth, Employment and Redistribution. A Macroeconomic Strategy", Pretoria: Ministry of Finance, South Africa.

DPRU (2006). "Graduate Unemployment in Post-Apartheid South Africa: Nature and Possible Policy Responses". Research Report Compiled for Business Leadership South Africa.

Development Policy Research Unit, University of Cape Town. March 2006.

Dunne, P. and Edwards, L. (2005). "Trade and Poverty in South Africa: Exploring the trade and employment linkage". Paper prepared for the Trade and Poverty Project. Available online at www.cssr.uct.ac.za/saldru.

Edwards, L. (2001a). "Globalisation and the skill bias of occupational employment in SA", South African Journal of Economics, 69(1): 40-71.

Edwards, L. (2001b). "Trade and the Structure of South African Production, 1984-97", Development Southern Africa, 18(4): 471-492.

Hoogeveen, J.G. and Özler, B. (2004). "Not Separate, Not Equal. Poverty and Inequality in PostApartheid South Africa". World Bank, Washington D.C.

Kakwani, N. (1993). "Poverty and Economic Growth with Application to Côte d'Ivoire", Review of Income and Wealth, 39(2): 121-139.

Lanjouw, P. and Ravallion, M. (1995). "Poverty and Household size", Economic Journal, (105): 1415-34.

Leibbrandt, M., Levinsohn, J. and McCrary, J. (2005a). "Income in South Africa Since the Fall of Apartheid", National Bureau of Economic Research, Working Paper 11384. 
Leibbrandt, M., Poswell, L., Naidoo, P., Welch, M. and Woolard, I. (2005b). "Measuring Recent Changes in South Africa Inequality and Poverty using 1996 and 2001 Census Data". Centre for Social Science Research Working Paper No. 84, Cape Town. August 2005.

Leibbrandt, M., Woolard, I. and Bhorat, H. (2001). "Understanding contemporary household inequality in South Africa". In Fighting Poverty: Labour Markets and Inequality in South Africa, edited by Bhorat, H., Leibbrandt, M., Maziya, M., Van der Berg, S. and Woolard, I. Cape Town: UCT Press.

Lewis, J.D. (2001). "Policies to Promote Growth and Employment in South Africa". World Bank, Washington.

Manuel, T. (2001). Budget Speech, 21 February 2001: National Treasury, South Africa.

May, J. (1998). "Poverty and Inequality in South Africa". Report prepared for the Office of the Executive Deputy President and the Inter-Ministerial Committee for Poverty and Inequality.

Meth, C. (2006). "What was the poverty headcount in 2004 and how does it compare to recent estimates by van der Berg et al? ", Unpublished Report. 18 May 2006.

Nattrass, N. (2000). "The Debate about Unemployment in the 1990s", Studies in Economics and Econometrics, 24(3): 73-90.

Oosthuizen, M. and Naidoo, P. (2005). "Change in Education: Evidence from National Household Surveys", Commissioned by The Education Foundation Trust. Development Policy Research Unit, University of Cape Town. February 2005.

Pauw, K. (2003). "Creating a 1995 OHS and a Combined OHS-IES Database in STATA", PROVIDE Technical Paper Series, 2003:2. PROVIDE Project, Elsenburg. Available online at www.elsenburg.com/provide.

Pauw, K. (2005). "Creating an IES-LFS 2000 Database in Stata", PROVIDE Technical Paper Series, 2005:1. PROVIDE Project, Elsenburg. Available online at www.elsenburg.com/provide.

Pauw, K., Leibbrandt, M., Edwards, L. and Dieden, S. (2006). "Trade and Poverty in South Africa: Traded sector employment and vulnerability", Report Prepared for the Trade and Poverty Project. Available online at www.saldru.uct.ac.za.

Statistics South Africa (2002). "Earning and spending in South Africa. Selected findings and comparisons from the income and expenditure surveys of October 1995 and October 2000". Statistics South Africa, Pretoria.

Taylor, V. (2002). "Transforming the Present - Protecting the Future". Report of the Committee of Inquiry into a Comprehensive System of Social Security for South Africa.

UNDP (2003). "South African Human Development Report 2003: The Challenge of Sustainable Development". Oxford University Press: UNDP South Africa.

Van der Berg, S. (2005). "Fiscal expenditure incidence in South Africa, 1995 and 2000". A report for the National Treasury. Department of Economics, University of Stellenbosch. 21 February 2005.

Van der Berg, S., Burger, R., Burger, R., Louw, M. and Yu, D. (2005). "Trends in poverty and inequality since the political transition". Paper presented at the TIPS/DPRU Forum 2005, 30 November - 1 December 2005, Glenburn Lodge, Gauteng. 
Van der Berg, S. and Louw, M. (2004). "Changing Patterns of South African Income Distribution: Towards Time Series Estimates of Distribution of Poverty", South African Journal of Economics, 72(3): 546-572.

Van der Berg, S., Nieftagodien, S. and Burger, R. (2004). "Consumption Patterns of South Africa's Rising Black Middle-Class: Correcting for Measurement Errors". Paper presented at the CSAE conference on Poverty Reduction, Growth and Human Development in Africa, Oxford, March 2004, March 2004,

Van Walbeek, C. (2006). "Official Revisions to South African National Accounts Data: Magnitude and Implications", Mimeo.

Woolard, I. (2003). "Impact of Government Programmes Using Administrative Data Sets: Social Assistance Grants", Project 6.2 of the Ten Year Review Research Programme. June 2003.

Available online at www.sarpn.org.za.

Woolard, I. and Leibbrandt, M. (2001). "Measuring Poverty in South Africa". In Fighting Poverty: Labour Markets and Inequality in South Africa, edited by Bhorat, H., Leibbrandt, M., Maziya, M., Van der Berg, S. and Woolard, I. Cape Town: UCT Press. 


\section{NOTES}

1. This paper forms part of a broader country study on cash transfers in South Africa. In a second paper, the authors consider in more depth the opportunities, challenges and constraints to expanding the social security net in South Africa.

2. As the income distributions change, this poverty line shifts, hence the term relative (as opposed to absolute) poverty line.

3. The LFS replaced the OHS in 1999. In 1995 and 2000 the survey samples were drawn on the same sample frame as in the IESs of the same years, so that, by merging the two, it is possible to form comprehensive datasets with both household-level income and expenditure data and person-level demographic and employment information. The latest IES was conducted in 2005 , but the data have not yet been released.

4. The sum of strict and broad unemployment shares as a percentage of the total labour force (employed and unemployed) will give the corresponding broad unemployment rate. The strict unemployment rate is calculated in a similar way, but assuming that the broad unemployed are non-participants.

5. GOS is defined as income arising from the ownership of physical and/or human capital, hence it is sometimes also referred to as 'mixed income'.

6. Although the SSA report does not elaborate much on that, the fact that the average household size shrank from about 4.44 members in 1995 to 3.88 in 2000 may account for the large differences between household-level and per capitalevel declines.

7. While the 1995 estimate was based on the IES 1995, it remains unclear from the report exactly where the income variable for 2002 was sourced from.

8. Various alternative sets of sampling weights - none of which was ever officially released by Statistics South Africa have been used by different researchers.

9. This can be ascribed to the inclusion of certain expenditures to the scaling of incomes and expenditures, and to the choice of sampling weights.

10. The approach usually followed in South African studies of this nature is to aggregate individual incomes at the household level, and then distribute this income uniformly across individuals in the household. Children under 18 years of age are also, therefore, typically included in such analyses.

11. See http://www.statssa.gov.za/keyindicators/cpi.asp. The CPI food index (metropolitan areas) and the CPI for all items (metropolitan areas) are compared in it.

12. Some sensitivity analysis is performed to gauge the effect that this has on poverty and inequality measures (for more on the subject, see Leibbrandt et al., 2005b).

13. Given the existing interest in the Post-Apartheid period, we focus mainly on their results for the 1995 to 2000 period.

14. Available only until 1996.

15. It could, of course, have to do with the sampling weights applied, although it can also be shown that the mean per capita income in the IES 2000 (for example) is well below the mean per capita income from the national accounts.

16. This section, as well as the following (section 3.2), draws largely on a report on growth, poverty and economic policy by Bhorat et al. (2005), unless otherwise cited.

17. Some controversy exists about employment performance in the latter part of the 1990s.

18. A loss of confidence occurred in 1996, shortly after the appointment of Trevor Manuel as Minister of Finance, and had a large impact on the value of the Rand. This was followed by the emerging market crisis of 1998, while the subsequent Argentinean and Zimbabwean crises and 'September 11, 2001' again took their toll. During that entire period, domestic socio-political problems (crime, labour regulations, tax regimes) caused instability and deterred investments up to at least the early 2000s (see Gelb, 2005, cited in Bhorat et al., 2005).

19. This section draws largely on analyses done for a DPRU project on graduate unemployment in South Africa (DPRU, 2006), unless otherwise cited.

20. These authors further decompose the changing labour demand patterns in order to gauge the relative importance of technical change versus structural change in the overall employment change and find that, although both are important, the former has had a greater impact in terms of the demands for different types of labour (skilled versus unskilled and low-skilled).

21. Examples of poor people losing their jobs in industries such as agriculture and textiles are abundant.

22. The same definition of poor and non-poor people used in section 2.1 applies here.

23. A comparison such as this should be made with care, especially since we are not dealing with panel data. To put it more correctly, people defined as poor in 1995 earned on average less, in real terms, than people defined as poor in 2000.

24. Poor are defined as the bottom 40 per cent of individuals, as ranked by pre-transfer per capita income. The ultra-poor are defined as the poorest 20 per cent.

25. At the time of Woolard's (2003) study, the CSG covered children up to the age of seven years. This has subsequently been raised to include children up to the age of fourteen. 


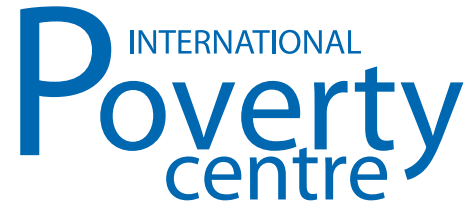

International Poverty Centre SBS - Ed. BNDES, $10^{\circ}$ andar 70076900 Brasilia DF Brazil

povertycentre@undp-povertycentre.org www.undp-povertycentre.org Telephone +55 6121055000 Fax +55 6121055001 